\title{
Bright Metal Coatings from Sustainable Electrolytes: The Effect of Molecular Additives on Electrodeposition of Nickel from a Deep Eutectic Solvent
}

\author{
Andrew P. Abbott ${ }^{1}$, Andrew Ballantyne ${ }^{1}$, Robert C. Harris ${ }^{1}$, Jamil A. Juma ${ }^{1,2}$ and Karl S. Ryder $*^{1}$ \\ ${ }^{1}$ Materials Centre, Department of Chemistry, University of Leicester, Leicester, UK LE1 7RH. \\ ${ }^{2}$ Department of Chemistry, University of Koya, Arbil, Iraq \\ e-mail: k.s.ryder@le.ac.uk; Fax: (+44) (0)116 2523789
}

\begin{abstract}
Organic and inorganic additives are often added to nickel electroplating solutions to improve surface finish, reduce roughness and promote uniform surface morphology of the coatings. Such additives are usually small molecules and often referred to as brighteners or levellers. However, there have been limited investigations into the effect of such additives on electrodeposition from ionic liquids (ILS) and deep eutectic solvents (DESs). Here we study the effect of four additives on electrolytic nickel plating from an ethyleneglycol based DES; these are nicotinic acid (NA), methylnicotinate (MN), 5,5dimethylhydantoin (DMH) and boric acid (BA). The additives show limited influence on the bulk $\mathrm{Ni}(\mathrm{II})$ speciation but have significant influence on the electrochemical behaviour of $\mathrm{Ni}$ deposition. Small concentrations (ca. $15 \mathrm{mM}$ ) of $\mathrm{NA}$ and $\mathrm{MN}$ show inhibition of $\mathrm{Ni}(\mathrm{II})$ reduction whereas high concentrations of $\mathrm{DMH}$ and $\mathrm{BA}$ are required for a modest difference in behaviour from the additive free system. NA and MN also show that they significantly alter the nucleation and growth mechanism when compared to the additive free system and those with DMH and BA. Each of the additive systems had the effect of producing brighter and flatter bulk electrodeposits with increased coating hardness but XRD shows that NA and MN direct crystal growth to the [111] orientation whereas DMH and BA direct crystal growth to the [220] orientation.
\end{abstract}

\section{Keywords}

Electroplating, nickel, deep eutectic solvents, additives, brightener, leveller, hardness. 


\section{Introduction}

It is estimated that $10^{5}$ metric tons of nickel and nickel salts were consumed worldwide in 2011 through nickel electrodeposition processes. ${ }^{1}$ Electrolytic nickel coatings are commonly applied as decorative and/or functional coatings as well as use in electroforming processes. Some of the functional benefits which $\mathrm{Ni}$ coatings provide are corrosion resistance, electrocatalysis and use in magnetic applications, with their deposition primarily occurring from aqueous solutions. ${ }^{2}$ The first practical $\mathrm{Ni}$ plating formulation was developed by Bottager in $1843^{3}$ and since that time the formulations have become increasingly complex and varied as methods were found to add increased functionality to the resulting coatings such as increased hardness, improved throwing power, reduced coating stress, ${ }^{4}$ improved adhesion and levelling/brightening. ${ }^{5}$

Typically, improved surface morphology (homogeneous coatings with low surface roughness) levelling/brightening of Ni coatings is achieved with the use of additives which modify the deposition mechanism to achieve the desired impact on the resultant coating. Levelling is the ability of an electroplating solution to preferentially deposit in recesses within a coating as opposed to protrusions and the levelling agents will typically have fast absorption and desorption. Common levelling agents for Ni plating include polyethyleneglycol and coumarin. Brightening is the ability of an electroplating solution to produce fine deposits with a grain size smaller than the wavelengths of visible light and having oriented grain structure while producing a smooth and even surface. Typically, both brighteners and levellers function by absorption onto the substrate surface in a specific manner. Brighteners for Ni electroplating are typically aromatic molecules with polar functional groups such as benzenesulfonic acid and saccharin (o-benzoic sulphonamide). ${ }^{6}$

Despite their maturity, aqueous deposition processes still possess significant limitations such as low current efficiency, coating embrittlement, stringent process control and bath complexity. ${ }^{2}$ As such the use of novel ionic liquid ${ }^{7}$ (IL) media and deep eutectic solvents ${ }^{8}$ (DES) are gaining attention. These solvent/electrolyte media offer potential improvements in process control/efficiency, environmental sustainability and functionality as well as access to reactive metal deposition not previously possible (for example Al). In addition, due to the fundamental differences between molecular solvents like water and ILS/DESs there are significant differences in the way metal films nucleate and grow on surfaces. ${ }^{9}$

DESs are systems formed from eutectic mixtures of Brønsted or Lewis acids and bases, typically mixtures of the salt choline chloride with small hydrogen bonding molecules such as ethyleneglycol or urea. $^{8}$ They have been used for the electrodeposition of a wide range of metal and alloy coatings including copper, ${ }^{10,11}$ tin, ${ }^{12-14}$ zinc, $^{15,16}$ chromium, ${ }^{17,18}$ zinc/nickel ${ }^{19}$ and zinc/tin. ${ }^{20}$

Thus far there have been limited studies investigating the additive effect in DESs. The majority of published research has studied the impact of complexing agents on the electrodeposition, for example of $\mathrm{Zn}$ and $\mathrm{Sn}$. These have the effect of altering the bulk metal ion speciation as opposed to operating as a brightener/leveller in the conventional way. ${ }^{21-25}$ Freudenberger et al investigated the effect of nicotinic acid on Pd electrodeposition finding that it did perform as an effective brightener in the DES known as Reline (a 2:1 molar mixture of urea and choline chloride). ${ }^{26}$ Guo et al also studied the additive effect of nicotinic acid in Reline for the electrodeposition of $\mathrm{Ni}$ additionally finding that nicotinic acid has the effect of refining the grain size of Ni deposits in this case. ${ }^{2}$ However, Reline has 
a relatively high viscosity ( $300 \mathrm{CP}$ at $298 \mathrm{~K}$ ) and has relatively poor thermal and electrochemical stability.

In the present study, we investigate the effect of the common additives nicotinic acid (NA), methylnicotinoate (MN), 5,5-dimethylhydantoin (DMH) and boric acid (BA) on the electrodeposition of nickel from a eutectic mixture of ethyeneglycol and choline chloride, commonly known as Ethaline. These additives were chosen as a sample of those small molecule species that are in common use as levellers and brighteners in aqueous process for metal plating. A study of speciation using UV-visible spectroscopy shows limited impact on nickel ion bulk speciation. Cyclic voltammetry, chronoamperometry and the quartz crystal microbalance are used to elucidate aspects of the nickel ion reduction with these additives. This is then used to describe the additive effect on subsequent nickel electrodeposition morphology, crystal structure and coating hardness.

\section{Experimental}

Choline chloride, $\left[\mathrm{HOC}_{2} \mathrm{H}_{4} \mathrm{~N}\left(\mathrm{CH}_{3}\right)_{3} \mathrm{Cl}\right](\mathrm{ChCl})$ (Aldrich $\left.99 \%\right)$ was recrystallised from absolute ethanol, filtered and dried under vacuum. Ethylene glycol (EG) (Aldrich + $99 \%$ ), was used as received. The two components have been mixed together by stirring (in a 1:2 molar ratio of $\mathrm{ChCl}$ : hydrogen bond donor) at $60{ }^{\circ} \mathrm{C}$ until a homogeneous, colourless liquid formed. The nickel salt; $\mathrm{NiCl}_{2} \cdot 6 \mathrm{H}_{2} \mathrm{O}$ (Aldrich $\geq 98 \%$ ) was used as received. The concentration of nickel in all solutions was $0.6 \mathrm{~mol} \mathrm{dm}^{-3}$ unless specified otherwise. The additives and concentrations used were nicotinic acid (NA, $15 \mathrm{mM}$ ) (Sigma $\geq 99.5 \%$ ), methyl nicotinate (MN, $15 \mathrm{mM}$ ) (Aldrich 97\%), 5,5 dimethyl hydantoin ( $\mathrm{DMH}, 0.65 \mathrm{M}$ ) (Sigma $\geq 99.5 \%$ ) and boric acid ( $\mathrm{BH}, 0.65 \mathrm{M}$ ) (Analar 99.8\%) were all used as received. The structures of the additives can be seen in Table 1.

UV-visible spectra were recorded with a Shimadzu model UV-1601 spectrophotometer with cell path length of $1 \mathrm{~cm}$. Values for $I_{\max }$ were determined using the spectrophotometer's built-in peak-pick feature, using UV-probe software.

Cyclic voltammetric and chronoamperometric / chronocoulometric investigations were performed on an Autolab PGSTAR12 potentiostat controlled with GPES2 software. A three electrode system comprising a $1 \mathrm{~mm}$ Pt disc working electrode, Pt flag counter electrode with an $\mathrm{Ag}$ wire reference electrode acting as a pseudo $\mathrm{Ag} / \mathrm{Ag}+$ reference electrode due to the high concentration of $\mathrm{Cl}^{-}$was the experimental method employed. The working electrode was polished with $0.05 \mu \mathrm{m} \psi$-alumina paste followed by washing with deionised water and acetone prior to every experiment. Voltammetric measurements were performed at $90{ }^{\circ} \mathrm{C}$.

Acoustic impedance measurements under electrochemical control were performed as above with the exception that the Pt surface of the quartz crystal was used as the working electrode. The crystal was $10 \mathrm{MHz}$ polished AT-cut quartz with a piezoelectric active electrode area of $0.23 \mathrm{~cm}^{2}$. Impedance spectra were recorded using a Hewlett Packard HP8751A network analyser, connected to a HP87512A transmission/reflection unit via a $50 \Omega$ coaxial cable, such that the centre of the spectrum was near the resonance. The sweep width was $150 \mathrm{kHz}$. Measured data were fitted to a Lorentzian equivalent circuit model as reported previously. ${ }^{27}$ 
Bulk electrolysis was performed using copper sheet ( $50 \mathrm{~mm} \times 42 \mathrm{~mm} \times 1 \mathrm{~mm}$ ) which were degreased with anopol cleaner $\mathrm{C}$ for 5 mins and etched with an aqueous $0.87 \mathrm{M}\left(\mathrm{NH}_{4}\right)_{2} \mathrm{~S}_{2} \mathrm{O}_{7}$ (Aldrich) and $0.2 \mathrm{M}$ $\mathrm{H}_{2} \mathrm{SO}_{4}$ (Fisher) solution. The Cu plates were rinsed and dried after each step followed by immersion into the plating liquid. An iridium oxide coated Ti mesh electrode was used as an anode. The solution temperature was $90^{\circ} \mathrm{C}$ and experiments were performed at $1.2 \mathrm{~A} \mathrm{dm}^{-2}$ for 20 mins after which the substrate was removed from solution and washed with water and acetone.

Scanning electron microscope (SEM) images were recorded with a Philips XL-30 Field Emission Gun SEM equipped with a Bruker AXS XFlash 4010 EDS detector operating at $25 \mathrm{kV}$. Secondary electron images were recorded with a working distance of $5 \mathrm{~mm}$ and an accelerating voltage of $20 \mathrm{kV}$. Samples for cross section were prepared through encasing in Conductomount (Met-Prep) on a Struers Labopress-3 with heating at $180{ }^{\circ} \mathrm{C}$ for 3 mins at $25 \mathrm{kN}$, followed by water cooling for 3 mins. Subsequently, the cylindrical samples were ground on 240 grit SiC abrasive discs (MetPrep) until the copper sheet was observable, followed by polishing with increasing grit SiC abrasive discs (MetPrep), polishing with 4 and $1 \mu \mathrm{m}$ diamond paste and a final polishing step using $0.05 \mu \mathrm{m}$ alumina (MetPrep).

Powder XRD analysis was carried out using a Bruker D8 Advance powder diffractometer with DaVinci. This was equipped with a LynxEye Linear Position Sensitive Detector and a 90-position autosampler. The instrument runs the DIFFRACplus software suite, which includes EVA for search/match and phase identification.

Hardness of the electrodeposits were evaluated from their resistance to indentation from the force and depth of indentation on a Mitutoyo model MVK-G100 hardness meter. The specimens were indented using a force of (50 gf) and a loading rate of $0.1 \mathrm{~mm} \mathrm{~s}^{-1}$ for $10 \mathrm{~s}$. The Vickers number was obtained by dividing the kg-force load by the square area of indentation of the standard probe.

\section{Results and discussion}

\section{Metal ion speciation}

Metal ion speciation is one of many factors affecting metal electrodeposition and as such has received much study for both ILs ${ }^{28}$ and DES. ${ }^{29}$ Typically, the speciation of a metal salt in an IL is dominated by either the counter ion of the dissolved metal salt and/or the anion component of the ionic liquid ${ }^{30,31}$ unless additional ligands are included in the formulation. ${ }^{32}$ Despite the increasing complexity in the chemical variety of DES electrolytes, the ion speciation of dissolved metal salts is mostly dominated by the formation of low coordination number chloro complexes such as $\mathrm{AuCl}$ which forms the linear $\left[\mathrm{AuCl}_{2}\right]^{-}$complex ${ }^{33}$ or $\mathrm{CuCl}_{2}$ which forms the tetrahedral $\left[\mathrm{CuCl}_{4}\right]^{2-}$ complex ${ }^{29}$ when dissolved in the DES Ethaline at room temperature. However, $\mathrm{Ni}$ is an unusual case in that, when $\mathrm{NiCl}, \mathrm{Ni}\left(\mathrm{NO}_{3}\right)_{2}$ or $\mathrm{NiSO}_{4}$ salts were dissolved in Ethaline, ethyleneglycol (Eg) acted as a chelating ligand with the $\mathrm{Ni}^{2+}$ surrounded by three glycol molecules forming the $\left[\mathrm{Ni}(\mathrm{Eg})_{3}\right]^{2+}$ complex. In addition, it has also been demonstrated that $\mathrm{NiCl}_{2}$ in Ethaline is also thermochromic in that it forms a pale green solution at room temp yet at the elevated temperatures $\left(T>90^{\circ} \mathrm{C}\right)$ it will form a deep blue solution. ${ }^{34}$ This temperature behaviour (change in colour) is evidenced by the evolution of UV-visible absorbance spectrum shown in Figure 1. The black line in Figure $\mathbf{1}$ (a) shows the UV-visible spectrum for a $15 \mathrm{mM}$ solution of $\mathrm{NiCl}_{2}$ in Ethaline at room temperature. Two absorbance bands are visible, centred at 425 
$\mathrm{nm}$ (band 1) and 655-715 $\mathrm{nm}$ (band 2) respectively. This is consistent with that seen previously with the first band attributed to the ${ }^{3} \mathrm{~A}_{2 \mathrm{~g}}(\mathrm{~F}) \rightarrow{ }^{3} \mathrm{~T}_{1 \mathrm{~g}}(\mathrm{P})$ transition of the octahedral $\mathrm{Ni}^{2+}$ ion. ${ }^{35}$ In aqueous media this is commonly the $\mathrm{Ni}\left(6 \mathrm{H}_{2} \mathrm{O}\right)^{2+}$ ion and in Ethaline this was attributed to the tris-ethyleneglycol complex. ${ }^{36}$ The black line in Figure 1 (b) shows the UV-vis spectrum of the same solution at $90{ }^{\circ} \mathrm{C}$. The initial band at $425 \mathrm{~nm}$ is still present but with a slightly lower intensity. The largest change is that band $2(655-715 \mathrm{~nm})$ has now formed two peaks and its intensity has increased significantly. This was attributed to the formation of the tetrahedral anionic nickel complex $\left[\mathrm{NiCl}_{4}\right]^{2-}$ and it's ${ }^{3} \mathrm{~T}_{1}(\mathrm{~F}) \rightarrow^{3} \mathrm{~T}_{1}(\mathrm{P})$ transition. This structure is more consistent with the behaviour of other metal ions. As such $\mathrm{NiCl}_{2}$ is themochromic in Ethaline as the tris-ethyleneglycol complex is favoured at low temperatures but the tetrahedral chloride complex is progressively more dominant as the temperature increases. The reduction process of these species are indicated in Scheme 1.

$$
\begin{aligned}
& {\left[\mathrm{Ni}(\mathrm{Eg})_{3}\right]^{2+}+2 \mathrm{e}-\rightarrow \mathrm{Ni}+3 \mathrm{Eg}} \\
& {\left[\mathrm{NiCl}_{4}\right]^{2-}+2 \mathrm{e}^{-} \rightarrow \mathrm{Ni}+4 \mathrm{Cl}^{-}}
\end{aligned}
$$

\section{Scheme 1}

The use of an additive in electrochemical plating may cause an effect in a number of ways;

1) It may change the bulk speciation of the metal ion. ${ }^{33}$

2) It may promote the formation of transient species in the solution close to the electrode surface that alter electrochemical reaction.

3) It may adsorb onto the surface influencing the kinetics of nucleation and growth. ${ }^{1}$

UV-visible spectroscopy offers the opportunity to obtain insight as to the extent to which an additive affects the bulk solution metal speciation. The UV-visible data for solutions of $\mathrm{NiCl}_{2}\left(\mathrm{H}_{2} \mathrm{O}\right)_{6}(15 \mathrm{mM})$ in Ethaline as a function of additive at $25{ }^{\circ} \mathrm{C}$ and $90{ }^{\circ} \mathrm{C}$ are presented as Figure 1. Here, the additives, nicotinic acid (NA), methylnicotinoate (MN), 5,5-dimethylhydantoin (DMH) and boric acid (BA) are all present in a moderate molar excess. At room temperature the peak positions of both band 1 and band 2 remain invariant with additive compared with the native solution. This suggests that the speciation of $\mathrm{Ni}^{2+}$ in the presence of these additives remains unchanged with respect to the native DES solution despite the comparatively high concentration of additive.

At $90{ }^{\circ} \mathrm{C}$ the band 2 (that attributed to the ${ }^{3} \mathrm{~T}_{1}(\mathrm{~F}) \rightarrow^{3} \mathrm{~T}_{1}(\mathrm{P})$ ) transition of the tetrahedral chloro complex, $\left[\mathrm{NiCl}_{4}\right]^{2-}$, still displays two peaks with consistency of shape and peak absorbance suggesting that this species is still progressively dominant at higher temps. The peak in band 1 is still present for all additives, occurring at a similar intensity and peak position for the solutions containing DMH and BA suggesting that $\left[\mathrm{Ni}(\mathrm{eg})_{3}\right]^{2+}$ is the structure relating to this peak. However, for those solutions containing NA and MN the peak position has shifted to slightly lower wavelength as well as exhibiting higher intensity. Since the shift in position and intensity are relatively small we interpret this peak as arising from the ${ }^{3} \mathrm{~A}_{2 g}(\mathrm{~F}) \rightarrow{ }^{3} \mathrm{~T}_{1 \mathrm{~g}}(\mathrm{P})$ transition from an octahedral complex. However, the small but significant change in position and shape of the band 1 peak suggests that some of the ethyleneglycol molecules of the octahedral cationic structure may have exchanged with NA or MN.

In summary, at low temperatures there is no evidence that the additives (present in slight molar excess) effect the bulk speciation of $\mathrm{Ni}^{2+}$ in the DES. At the higher temperatures the $\mathrm{Ni}^{2+}$ speciation is still dominated by the DES anion as evidenced by the band 2 peaks (and the colour) associated with 
$\left[\mathrm{NiCl}_{4}\right]^{2}$. However, there is some evidence of ligand substitution in the cases of MN and NA in the residual concentration of the octahedral complex present in low concentration at high temperature.

\section{Cyclic voltammetric (CV) studies}

In previous studies it has been shown that, as with speciation, the electrochemical properties of $\mathrm{Ni}^{2+}$ on Pt in Ethaline showed a marked evolution in behaviour with increasing temperature. ${ }^{34,35}$ At low temperatures and concentrations there are no discernible deposition and stripping responses during cyclic voltammetric scans. However, once the temperature and concentration is increased towards and above $80{ }^{\circ} \mathrm{C}$ a quasi-reversible deposition/stripping electrochemical response is observed. At these elevated temperatures the $\mathrm{CV}$ responses for the $\mathrm{Ni}^{2+}$ in Ethaline are characterised by a cathodic deposition wave at ca. -0.4 to $-0.6 \mathrm{~V}$ and a corresponding anodic stripping wave at between $0.0 \mathrm{~V}$ and $+0.2 \mathrm{~V}$. This can be seen for the black line in Figure $\mathbf{2}$ (a) where there is a cathodic current with an onset potential of $-0.34 \mathrm{~V}$ and peak magnitude of approximately $-380 \mu \mathrm{A}$ once the potential has been swept $0.6 \mathrm{~V}$ (w.r.t. Ag wire pseudo reference). The corresponding anodic stripping feature is seen at $+0.2 \mathrm{~V}$.

To elucidate the effect of $\mathrm{NA}$ on the electrochemical properties of $\mathrm{Ni}^{2+}$, a solution of $0.6 \mathrm{M} \mathrm{NiCl}_{2}$ in Ethaline was sequentially doped with increasing concentrations of NA with the resulting voltammetric scans shown in Figure $\mathbf{2}$ (a). The inclusion NA has a considerable impact on the appearance of the voltammogram, even at low relative concentrations $(5 \mathrm{mM})$ of NA.

Most notably, the effect of $5 \mathrm{mM} \mathrm{NA}$ on the $\mathrm{Ni}^{2+} \mathrm{CV}$ is to change the shape and potential of the anodic stripping wave. The wave shape becomes much sharper and symmetrical whilst the onset potential is shifted in the cathodic direction to $-0.10 \mathrm{~V}$. Both of these factors indicate that $\mathrm{Ni}$ dissolution in the presence of NA is energetically more favourable and occurs more rapidly than in the native Ethaline DES. At this low concentration the NA has less pronounced effect on the cathodic portion of the CV. However, at higher concentrations of NA (10 and $15 \mathrm{mM}$ ), the cathodic current becomes suppressed indicating that $\mathrm{Ni}$ metal deposition is slower in the presence of NA. For example at the vertex potential, $-0.6 \mathrm{~V}$, Figure $2(\mathrm{a})$, the cathodic current in neat Ethaline is measured at $-380 \mu \mathrm{A}$; in the presence of $15 \mathrm{mM}$ NA this is reduced to $-240 \mu \mathrm{A}$. The $\mathrm{CV}$ s indicate that NA is inhibiting the deposition process, due to the lower currents and accelerating the stripping process due to the change in peak shape as consistent with that seen for both nickel and copper other systems where nicotinic acid is present as an additive. ${ }^{2,37}$

An even more pronounced effect is seen where $M N$ is used as an additive, Figure $\mathbf{2}$ (b), the cathodic inhibition is greater with a current of $-180 \mu \mathrm{A}$ at $-0.6 \mathrm{~V}$ (w.r.t. Ag wire). Again, a rapid increase in the anodic current once a stripping potential has been reached is observed and the anodic onset potential for stripping has decreased to $-0.10 \mathrm{~V}$ in the presence of $\mathrm{MN}$.

In addition, where either NA or MN is added to the DES there emerge two anodic stripping features, Figure 1 (a) and (b). This type of effect is most often interpreted as the stripping of two phases of morphologies of crystal growth. In this case it is likely that the NA and MN are facilitating the stripping of $\mathrm{Ni}$ metal from specific faces of crystal growth by preferential adsorption. This hypothesis is 
strengthened by XRD data (presented later in this manuscript) which show that the additives are capable of influencing the orientation of crystal growth during deposition.

In the case of $\mathrm{NA}$ and $\mathrm{MN}$ the maximum concentration of additive studied is $15 \mathrm{mM}, 1.5$ orders of magnitude lower than the concentration of the $\mathrm{Ni}$ metal ion. Despite this comparatively low concentration there has been a significant impact on the Ni plating behaviour suggesting that the additive mode of action is adsorption onto the substrate surface leading to inhibition of the metal deposition. ${ }^{38}$ The observation that $\mathrm{MN}$ is more effective than NA at attenuating the electrochemical reduction of $\mathrm{Ni}^{2+}$ ions in Ethaline, suggests that adsorption of $\mathrm{NA}$ and $\mathrm{MN}$ on the surface occurs through the pyridine nitrogen atom. This is known to be the case on gold substrates. Assuming that this is the case here, the end of the adsorbed molecule facing the solution interface would consist of either a carboxylic acid (NA) or a methyl ester (MN). In this scenario it is likely that the dissolved $\mathrm{Ni}^{2+}$ metal ion would interact more strongly with the acid functionalised surface such that electrochemical reduction at this surface was more facile than at the ester functionalised surface.

In contrast, both $\mathrm{DMH}$ and BA have a considerably lower impact on the voltammetric potential scans, shown in Figure $\mathbf{2}$ (c) and (d). In order to observe any appreciable difference in both the cathodic and anodic sweep a much higher concentration of DMH was required. For example, an approximately $50 \%$ reduction in peak height of the anodic stripping peak was observed at a concentration of $650 \mathrm{mM}$ $\mathrm{DMH}$. Where BA was used, an equimolar concentration BA was required to produce any impact on the $\mathrm{CV}$ with only a modest reduction in anodic peak current observed. Because of the contrast in behaviour between the nicotinic additives compared with DMH and BA it is likely that their mechanism of operation is different. $\mathrm{DMH}$ and BA may not act by strong adsorption onto the electrode surface but may instead act as a leveller as they poorly inhibit the electrode reaction with $\mathrm{Ni}$ in solution. ${ }^{1}$ Published literature show that BA retards Ni deposition in aqueous media suggesting that its influence in DESs may be different to aqueous systems. ${ }^{39}$

Figure 3 shows the cyclic voltammograms of the respective additives in Ethaline with no $\mathrm{Ni}^{2+}$ present in solution. Figure 3 (a) shows the CVs for NA at concentrations of 0, 5, 10, 15 and 20 mM NA which show an electrochemically reversible redox system with increasing peak current with concentration. This is likely to be the reduction of hydrogen from the acid group as this is not present in the CV for $\mathrm{MN}$ (Figure $\mathbf{3}$ (b)) and the replacement of the acid group in NA for an ester in MN is the only difference in the structure of the two molecules. Studies of the electrochemistry of NA in aqueous solution have shown that the response is dependent on $\mathrm{pH}$, as might be expected but there are, to our knowledge, no similar studies in DES media. The most important feature of these CV's, Figure $\mathbf{3}(\mathbf{a})$, is that while the peak is clear on the current scale shown, the current magnitude is low when compared to that when $\mathrm{Ni}$ is present in solution suggesting that Faradaic charge associated with this process should not unduly affect the current efficiency of the process.

In the case of $\mathrm{DMH}$ and $\mathrm{BA}$ background cathodic currents are high when the potential is swept to a negative potential > $-0.5 \mathrm{~V}$. If these profiles were representative for the current due to the additive during cyclic voltammogram where $\mathrm{Ni}$ was present in solution this would suggest that the $\mathrm{Ni}$ deposition process would be very inefficient. However, in the case of these two additives the cathodic deposition current and anodic stripping currents are very similar meaning that it is likely that the process is close to $100 \%$ efficient. One possibility for this discrepancy is that on the CVs in Figure $\mathbf{3}$ (c) and (d) the substrate is Pt, however during deposition the substrate surface is constantly evolving with 
$\mathrm{Ni}$ being deposited on the surface. Consequently, the kinetics of $\mathrm{H}_{2}$ evolution may be slower on $\mathrm{Ni}$ than on Pt in this medium and at these potentials.

\section{Nucleation mechanisms}

The early stages of electrodeposition can provide important insights into the mechanism by which metal films nucleate and grow, often with important ramifications for the properties of bulk deposits such as smoothness and brightness. Chronamperometric methods have been used extensively to probe nucleation and growth mechanisms, in particular the form of the time-dependant current profiles can be modelled mathematically as described by Scharifker and Hills. ${ }^{40,41}$ According to these simple models there are two limiting mechanisms for nucleation; instantaneous and progressive. Instantaneous nucleation represents the slow growth of a static number of nuclei on a small number of active sites which form instantaneously once there is sufficient electrochemical driving force for electrodeposition to occur, i.e. at the beginning of the deposition phase of the experiment. Progressive nucleation corresponds to fast nucleation across many sites with nucleation occurring continuously throughout the electroreduction experiment.

The models for instantaneous and progressive nucleation are given in Equations $\mathbf{1}$ and $\mathbf{2}$ respectively. ${ }^{\ddagger}$ In this case, $t_{\mathrm{m}}$, is the time at which the current peaks at a maximum and, $i_{\mathrm{m}}$, is the current at that point and, $i$, is the current at a given time, $t$. These transforms are especially useful as they describe electrochemical deposition in three stages: Stage 1 describes the formation and growth of nuclei on the substrate surface $\left(t / t_{\mathrm{m}}<1\right)$, Stage 2 describes the coalescence of growing nuclei and the overlap of diffusion zones around them $\left(t / t_{\mathrm{m}} \approx 1\right)$ and Stage 3 describes the subsequent growth of the metal layer $\left(t / t_{m}>1\right)$.

$$
\begin{array}{ll}
\frac{i}{i_{m}^{2}}=\frac{1.9542}{\frac{t}{t_{m}}}\left\{1-\exp \left[-1.2654\left(\frac{t}{t_{m}}\right)\right]\right\}^{2} & \text { Equation } 1 \text { (Instantaneous) } \\
\frac{i}{i_{m}^{2}}=\frac{1.2254}{\frac{t}{t_{m}}}\left\{1-\exp \left[-2.3367\left(\frac{t}{t_{m}}\right)\right]^{2}\right\}^{2} & \text { Equation } 2 \text { (Progressive) }
\end{array}
$$

Figure 4 (a) (inset) shows the raw data for the chronoamperometry experiment from a $0.6 \mathrm{M} \mathrm{NiCl}_{2}$ solution in Ethaline at $90{ }^{\circ} \mathrm{C}$ where the potential at a Pt working electrode was held at $+0.6 \mathrm{~V}$ (w.r.t. silver wire pseudo reference) for $10 \mathrm{~s}$ followed by stepping the potential to $-0.4 \mathrm{~V}$ at which point deposition of $\mathrm{Ni}$ started to occur. After approximately $0.2 \mathrm{~s}$ the current reaches a peak and this was defined as the time at maximum current, $t_{\mathrm{m}}$. The normalised $i(t)$ data were then plotted against the theoretical models for instantaneous and progressive nucleation, as shown in Figure $\mathbf{4}$ (a). The current data in the absence of additive show that at relatively short times the mechanism of nucleation and growth of the $\mathrm{Ni}$ metal film is most closely represented by an instantaneous model, indicating that once nuclei had formed it was favourable for them to grow rather than the continuous generation of

\footnotetext{
₹ The equations 1 and 2 are used in this form, consistent with many other comparative analysis of electrochemical film growth. The numerical terms are collections of physical constants that include the Faraday constant, and terms describing the diffusion and rheology of the electrolyte. These numerical terms were originally evaluated for aqueous systems, however, the current study is carried out in DES which is a more viscous medium. Notwithstanding this, the qualitative and comparative arguments that we present here are unaffected.
} 
new nuclei. At longer times, $t / t_{m}>4$, the normalised current profile shows that growth of the metal film is more rapid than predicted by either model.

In operando, the deposition potential for bulk electroplating of Ni would more likely be fixed at a value greatly in excess of $-0.4 \mathrm{~V}$, in order to increase rate of deposition. Consequentially, as the overpotential (driving force) increases the mechanisms tend towards progressive nucleation. ${ }^{40}$ The sensitivity of mechanism to applied potential, concentration and temperature is well known for many systems and makes the selection of initial conditions for a study difficult. However, when considering the comparison of different additives, investigations at small overpotentials can provide important insights into the varying behaviour of these systems. In addition, the overpotential for these studies $(-0.4 \mathrm{~V})$ was chosen to enable the identification and measurement of the coordinate position, $i_{\mathrm{m}}, t_{\mathrm{m}}$, for the current nucleation peak.

Figures 4 (b) and (c) shows the reduced variant plot for a $0.6 \mathrm{M} \mathrm{NiCl}_{2}$ in Ethaline solution with added $15 \mathrm{mM}$ NA or MN respectively. Figure 4 (b) shows clearly that the NA additive has changed the nucleation mechanism and that in this case at all times the measured data show a good fit to a progressive model. The data presented in Figure $\mathbf{4}$ (c) also shows that at short times, during the early phases of nucleation and growth, the mechanism in the presence of the $\mathrm{MN}$ additive has changed to progressive. At longer times, however, the growth profile does not fit well to either model. We have demonstrated in the CV studies that low concentrations of NA or MN in the plating solution was enough to cause large differences in the electrochemical behaviour and the same is true for the nucleation studies.

Figures 4 (d) and (e) show the reduced current fits where the additives DMH and BA are present. In contrast with the nicotinate additives, these formulations follow an instantaneous mechanism as is consistent with the example where no additives are present, Figure 4 (a).

The $\mathrm{CV}$ and growth mechanism studies show that NA and $\mathrm{MN}$ have a lot of parallels in their behaviour, as may be expected due to the similarity in their structure and as such their absorption mechanisms on the substrate surface are likely to be similar. The electrochemical effect of these additives is also very different from that where no additive is present. However, high concentrations of DMH and BA give limited changes to both the electrochemical deposition/stripping, as analysed by cyclic voltammetry, and the growth mechanistic properties. This is also consistent with the behaviour observed in similar systems for Co deposition where the additive free, DMH and BA systems tended toward instantaneous nucleation phenomena and the nicotinate systems tended towards progressive phenomena.

\section{Chronocoulometry}

For Faradaic processes the time-dependant current decay, $i(t)$, during the period, $t>t_{\mathrm{m}}$ (Stage 3, above), is predicted to follow the Cottrell equation, Equation 3, where the current at a given time, $t$, is proportional to $t^{-1 / 2}$. Here, $D$, is the diffusion coefficient of the metal ion in solution, $n$, is the electron stoichiometry, $C$, is the bulk concentration of metal ion, $A$, is the surface area of the electrode and $F$ is Faraday constant. The integrated Cottrell equation is provided in Equation 4 which describes the overall charge consumed, $Q$, during the reaction. ${ }^{42}$ 


$$
\begin{array}{ll}
I=\frac{n F A C_{0} \sqrt{D}}{\sqrt{\pi t}} & \text { Equation 3 } \\
Q=\frac{2 n F A C_{0} D^{1 / 2} t^{1 / 2}}{\pi^{1 / 2}} & \text { Equation 4 }
\end{array}
$$

Equation 4 predicts that for Faradaic processes the total charge, $Q$, is linearly related to the square root of the elapsed time. Figure 5 shows plots of charge versus $t^{1 / 2}$ for $0.6 \mathrm{M}$ solutions of $\mathrm{NiCl}_{2}$ in Ethaline with and without additives for the data, $i(t)$, presented in Figure 4. Each of these systems follow non-linear trends with the rate of charge increase becoming faster with increasing time for all cases. This may be due to the high concentration of Ni present in the solution. Additionally, if the morphology of the deposit is rough then the area of the electrode also increases with time. As such, no attempts have been made to predict diffusion coefficients from these data but some interesting trends in behaviour can be observed nonetheless.

The black line in Figure 5 represents the curve for the solution corresponding to the deposition of $\mathrm{Ni}$ from Ethaline without additive. Here it can be seen that the charge passed at any time is significantly lower than in each of the systems where additives are present. This effect is especially pronounced at longer times. This contrasts to that observed for the CV data where the solution without additives typically exhibited higher current profiles during the cathodic deposition when compared to those with additives, Figure $\mathbf{2}$. In this case however, deposition is occurring over a much longer timescale than is the case during the CV scan. Consequently, what we observe in the chronoamperometric experiment is the bulk equilibrium growth rate for which the limiting factors (such as area, solution rheology and mass-transport) may be very different to those on the shorter scale of the CV. Additionally, the nucleation and growth rates observed in the CV, Figure $\mathbf{2}$, and in the very early stages of the potential step experiment, Figure 4, may be dominated by adsorption of either $\mathrm{Ni}^{2+}$ metal ion, or additive, on the Pt electrode surface, whereas in the case of bulk electrolysis observed at longer time scales the substrate is completely covered and sustained metal film growth is occurring on newly deposited nickel.

Interestingly, a differing response for the two different types of additives was discernible with overall charge for the nicotinic additives higher than that of the $\mathrm{DMH}$ and $\mathrm{BA}$, again providing further evidence for a different deposition mechanism for each of these systems.

\section{Electro-gravimetric studies by Quartz Crystal Microbalance}

Current efficiency is an important factor in understanding the efficacy of an electrodeposition process. Current efficiency is quantified by the ratio of measured mass deposited, for a known amount of charge passed during electrolysis, with the expected mass based on the Faraday equation. Furthermore, the current efficiency can vary in the duration of a process and may be affected by the availability of reducible species or by changes in mass transport regime (electrolyte rheology) or electrode kinetics (caused for example by passivation effects). Simply weighing the total mass deposited at the end of an electrodeposition will give an overall measure of current efficiency but will not provide any temporal insights. The electrochemical quartz crystal microbalance (EQCM) is a powerful gravimetric technique for evaluating the efficiency of electrochemical processes due to its ability to monitor in situ the mass change during and electrochemical experiment. The mass change 
on a quartz crystal is linearly related to its resonance frequency as described by the Sauerbrey equation, Equation 5, where, $\Delta f / \mathrm{Hz}$, is the frequency change incurred by added mass, $f_{0} / \mathrm{Hz}$, is the resonant frequency of the crystal, $A / \mathrm{cm}^{2}$, is the piezoelectrically active surface area, $\rho_{\mathrm{q}} / \mathrm{g} \mathrm{cm}^{-3}$, is the density of quartz, $\mu_{\mathrm{q}} / \mathrm{g} \mathrm{cm}^{-1} \mathrm{~s}^{-2}$, is the shear modulus of quartz for an AT cut quartz crystal and $\Delta \mathrm{m} /$ $\mathrm{ng}$, is the added mass. For a $10 \mathrm{MHz}$ AT cut quartz crystal the Sauerbrey equation simplifies to give $\Delta f$ $=-1.1 \Delta m .^{43}$

$$
\Delta f=-\frac{2 f_{o}^{2}}{A \sqrt{\rho_{q} \mu_{q}}} \Delta m \quad \text { Equation } 5
$$

Platinum coated quartz crystals were used in order to maintain as much consistency as possible with previous electrochemical experiments. In a typical experiment the dry crystal resonance was recorded and monitored using an acoustic impedance method at $4 \mathrm{~s}$ intervals followed by submersion in the $\mathrm{Ni}$ plating solution containing Pt flag counter and $\mathrm{Ag}$ wire reference electrodes, at which point an identical chronoamperometric experiment to that detailed in Figure 5 was recorded. Figure $\mathbf{6}$ shows the corresponding mass/charge plot for Ni plating experiments with and without additives. Increase in mass has been calculated from the change in recorded frequency using the Sauerbrey equation. Examination of the acoustic impedance spectra before and after deposition confirmed that there were no associated viscoelastic losses and that the deposit was rigid. The corresponding charge for the Faradaic process was calculated by integration w.r.t. time of the chronoamperometric data.

In all cases the trend of increased mass with Faradic charge was approximately linear suggesting that the efficiency of the process remained consistent throughout the duration of the experiment. Importantly, this shows that there are no passivation effects. The data from the solution containing no additives, Figure 6 (black line), shows the greatest increase in mass per unit of charge indicating that this is the most efficient process.

The current efficiency of an electrochemical process can be quantified by the ratio of the measured mass (for a given charge consumption) to the expected mass and is described in Equation's $\mathbf{6}$ and $\mathbf{7}$.

$$
\begin{array}{ll}
\Delta m(\text { theoretical })=\left(\frac{Q}{F}\right)\left(\frac{M}{z}\right) & \text { Equation } 6 \\
\text { current efficiency }=\frac{\Delta m(\text { actual })}{\Delta m(\text { theoretical })} \times 100 & \text { Equation 7 }
\end{array}
$$

A value for the theoretical maximum amount of mass of a substance deposited, $\Delta m$ (theoretical) $/ \mathrm{g}$, can be calculated from the charge, $\mathrm{Q} / \mathrm{C}$, using Faraday's law, Equation 6, where, $M / \mathrm{g} \mathrm{mol}^{-1}$, is the relative molar mass of $\mathrm{Ni}$ and, $z$, is the electron stoichiometry (in this case 2 ). ${ }^{44}$ As EQCM provides a quantifiable value for mass deposited, the current efficiency can be calculated using Equation 7. Calculated values for the current efficiency are presented in Table 2. These data show that inclusion of the molecular additives has the general effect of reducing current efficiency from $90 \%$, in the case where only the $\mathrm{Ni}^{2+}$ salt is present, to around $80 \%$ in the presence of either NA, MN, DMH and BA. Interestingly, the effect on DMH and BA is slightly less pronounced than that of NA and MN despite the fact that the concertation of $D M H$ and $B A$ is much higher. The similarity in current efficiencies exhibited in the presence of $\mathrm{NA}(15 \mathrm{mM}), 78 \%$, and $\mathrm{BA}(600 \mathrm{mM}), 82 \%$, suggest that proton reduction is not a significant competitive reaction under these conditions. 
It has been demonstrated through CV studies that only small amounts of NA or MN are required to inhibit Ni deposition on a Pt surface, presumably due to strong adsorption of the additive onto the substrate, which may explain the slightly lower current efficiency for these formulations. In contrast, large concentrations of $\mathrm{DMH}$ and $\mathrm{BA}$ are required to obtain modest changes to the CVs indicating that the adsorption by these additives is weaker and as such has a lower influence on the current efficiency.

Another observation from these data is that, while current efficiency is slightly reduced through the use of additives, the total charge passed in a given time and the corresponding mass deposited is significantly higher in the presence of each additive. For the experiments shown in Figure 6 each electrodeposition was carried out over a period of $15 \mathrm{mins}$ (900 s). Where no additive is present the total charge passed during this is approximately $0.4 \mathrm{C}$, whereas in the presence of additives the total charge passed during the same time ranges between $0.9-1.0 \mathrm{C}$. This can also be seen in Figure 5 over the same $900 \mathrm{~s}$ time period $\left(t^{1 / 2}=30 \mathrm{~s}^{1 / 2}\right)$ where a significant increase in total charge was observed for all the experiments where additives were present in the solution. This demonstrates clearly that, under these conditions, despite the slightly lower current efficiencies the Ni films grow faster in the presence of the additive.

\section{Nickel deposit morphology}

We have demonstrated that the additives studied here have limited effect on bulk $\mathrm{Ni}^{2+}$ ion speciation yet have considerable influence on the rate of electrochemical nucleation and growth. In addition to this we have studied the influence of additives on the properties of bulk electrodeposition. To ensure consistency between coatings, to facilitate characterisation and comparison with other bulk coatings, copper was used as a standard substrate for bulk electrodeposition with an iridium oxide coated counter electrode. Bulk plating was performed at $90{ }^{\circ} \mathrm{C}$ for 20 mins under galvanostatic conditions at current density of $1.2 \mathrm{~A} \mathrm{dm}^{-2}$. In a recent paper we have demonstrated that uniform, bright coatings were obtained from solutions of $\mathrm{Ni}$ in the DES Ethaline, however there are notable differences in the deposition methodology. In the previous example plating was onto an Ni substrate, the concentration of $\mathrm{Ni}$ was higher $(1.1 \mathrm{M})$ and the plating times longer, all factors that will affect deposition behaviour and hence quality of the resulting coatings. ${ }^{34}$

An image of the coating produced under the conditions described here, where no additives are present in the plating solution, is shown in Figure $\mathbf{7}$ (a). Here, a dull, dark grey friable Ni coating covers the surface of the copper substrate. Figure $\mathbf{7}$ (b) shows an SEM image of the surface of the coating where microcrystals can be observed on the surface which give rise to the dull optical properties and poor mechanical integrity of the deposit. This is almost certainly due to the nature of crystal formation resulting from an instantaneous growth mechanism. In contrast, the samples produced where NA, $\mathrm{MN}, \mathrm{DMH}$ and BA were present, Figures $\mathbf{7}(\mathbf{d}),(\mathrm{g}),(\mathbf{j})$ and $(\mathrm{m})$ respectively, each produce bright, mirrorfinish, adherent and dense coatings with few identifiable distinguishing surface features. Analysis of the SEM images of the surface of each of these coatings, Figures $\mathbf{7}(\mathbf{e}),(\mathbf{h}),(\mathbf{k})$ and $(\mathbf{n})$ show limited features. Samples with bright coatings tend to have crystallites that are smaller than detectable at this resolution and as such it is unlikely that any features would be visible in the coatings, ${ }^{1}$ there are however some defects in the coating that can visualised on the surface in each of these cases. This type of coating morphology is typical of a much smaller crystal size that often results from a progressive mechanism. 
The thickness of the coatings, measured from the cross-sectional SEM images, Figure $\mathbf{7}(\mathbf{c}, \mathbf{f}, \mathbf{l}, \mathbf{l}, \mathbf{0})$, is in the range of $5-7 \mu \mathrm{m}$ where the additives are present and less than this, $c a .3 \mu \mathrm{m}$, in the absence of additive. This is consistent with our observations and indicative of a more rapid growth in the presence of the additives. These values of film thickness compare to an expectation of around $5 \mu \mathrm{m}$ based on a Faradaic calculation using the applied current density, $1.2 \mathrm{~A} \mathrm{dm}^{-2}$, the deposition time, $1200 \mathrm{~s}$, the bulk density of metallic nickel, $8.9 \mathrm{~g} \mathrm{~cm}^{-3}$ and an estimated current efficiency of $90 \%$. The agreement between expectation and measurement is generally good although the films grown in the presence of NA, MN and DMH are slightly thicker than anticipated. This may be because of variance in the sample thickness over the chosen measured area, or could reflect a higher current efficiency under galvanostatic conditions. Alternatively, the coating could be less dense than expected because of voids of hydrogen incorporation. There is little evidence of void formation from the SEM images but hydrogen incorporation and embrittlement is a concern. We are currently attempting to determine the hydrogen content of metal films grown in DES media in a separate study using neutron reflectometry and isotopic contrast methods. We expect to publish the results of this separately.

\section{X-ray Diffraction}

In Figure $\mathbf{8}$ we present the X-ray diffraction spectra for the coatings shown in Figure 7. Here there is evidence of diffraction peaks for the Ni [111], [200], [220] and [311] crystal phases highlighted which match closely with the literature values. Additionally there are other peaks relating to the underlying copper substrate. ${ }^{45}$ The XRD pattern for the Ni coating with no additives shows that a mixture of these phases is present indicating that growth of $\mathrm{Ni}$ crystallites can occur through a number of different orientations. However, the inclusion of additives during the deposition process directs crystallite growth. The additives present at low concentrations, NA and MN, primarily show crystal growth in the [111] and [311] orientation indicating that absorption of these additives onto the surface blocks [220] crystal growth. In contrast BA shows a large, sharp peak for the [220] orientation with limited responses seen for the other phases showing that this additive directs crystal growth in a very different way to NA and MN. DMH, which has thus far been classified as affecting Ni plating properties in a similar way to BA, shows an intermediate response where [220] growth was preferred when compared to the coating where no additives are present but not to the same extent as BA. The relative intensities of the Bragg diffraction peaks have been defined in Table 3.

An important insight from these data is that the additives direct crystal growth and that this has a controlling effect on the bulk morphology and mechanical integrity of the coating. This is presumably effected by the adsorption of additive onto a preferred crystal face blocking growth at that face. Qualitatively this would result in slower initial growth, observed in the CV, and the formation of additional nucleation sites as a function of time. The latter is evidenced from the fit of normalised chronoamperometric data to a progressive nucleation mechanism in the presence of NA or MN.

\section{Coating Hardness}

The hardness of a meatal coating is a characteristic that is often diagnostic in assessing the mechanical durability and wear resistance. Hardness is typically measured according to the Vickers protocol by 
indenting the coating to a depth of a few microns with a diamond tip of known geometry (squarebased pyramid with a tip angle of $136^{\circ}$ ) under a given applied force. The standard expression of hardness is defined as the ratio of the applied force with the surface area of the indentation and is

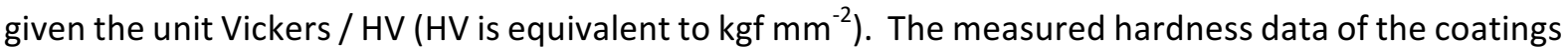
produced from $0.6 \mathrm{M} \mathrm{NiCl}_{2}$ in Ethaline with and without the additives $\mathrm{NA}, \mathrm{MN}, \mathrm{DMH}$ and $\mathrm{BH}$ are shown in Table 2. The data shown are the result of the average of five indentations and were performed over a representative area of the coating. The hardness value for the coating deposited in the absence of any additives is $389 \mathrm{HV}$ which matches those from commercial formulations such as Watts Ni but is significantly lower than that reported previously for Ni from Ethaline. ${ }^{34}$ This is unsurprising as the coating in this case was less uniform than that reported previously which was obtained from higher $\mathrm{Ni}$ ion concentrations and over longer deposition periods. However, once the additives have been included in the deposition medium hardness values of between 430 and $473 \mathrm{HV}$ are observed. These are comparable to the aqueous hard nickel values using additives such as ammonium chloride ${ }^{46}$ (c.a. 380-480 HV) and the highest reported values for Ni deposited from DESs (previously the hardness values for $\mathrm{Ni}$ coatings derived from DES media have not exceeded $400 \mathrm{HV}$ ). ${ }^{34}$

Consequently the bright, dense morphology / dense crystallite growth, of Ni coatings produced by the additives has given hardness values comparable to conventional aqueous hard nickel coatings and better than those previously observed for DES .

\section{Conclusions}

In this study we have shown that bright, hard adherent nickel coatings can be obtained at high current efficiency from a simple Deep Eutectic Solvent in the presence of low concentration of additive. Conventionally such coatings need complex aqueous mixtures of strong acids, metal salts, surfactants and buffers to maintain $\mathrm{pH}$ control. Hence the aqueous electrolyte baths require rigorous process control and maintenance during use. Here we offer insights into the actions of molecular additives on the electrodeposition of $\mathrm{Ni}$ in DES and show that control of the coating can be achieved through exploiting the difference in observed nucleation and growth mechanisms exhibited by the additives studied here.

The range of additives selected for study here, NA, MN, DMH and BA was chosen from those often used in aqueous processes. These additives seem to have little effect on the bulk speciation of $\mathrm{Ni}^{2+}$ metal ion in the DES, as evidenced by UV-visible spectroscopy, either at ambient or at elevated temperatures. However, the additives have a marked effect on the electrochemistry of the metal deposition and stripping in DES. In particular NA and MN, at low concentration, effect a change in nucleation and growth mechanism from instantaneous, in the absence of additive, to progressive. The effect on mechanism of the other additives is less clear but all additives give bright, smooth and adherent coatings compared to dull, rough and friable coatings produced from $\mathrm{Ni}^{2+}$ solutions in native Ethaline. For bulk electrodeposition, the additives have the effect of lowering current efficiency from $90 \%$ in the absence of additive to around $80 \%$, however, faster deposition rates were sustained in the DES solutions containing additives. In addition, we have shown that the additives direct crystal growth during bulk deposition and this provides a means of control over deposit morphology. Both NA and $\mathrm{MN}$ adsorb on the substrate through a different mechanism to BA and $\mathrm{DMH}$ as the former direct 
crystallite growth in the [111] and [311] orientations whereas DMH and BA direct crystallite growth in the [220] orientation. All of the brighteners produce Ni coatings with greater hardness than where no additive is present with the highest value observed for the coating where $\mathrm{MN}$ was present in the solution.

\section{Acknowledgements}

The financial support of Ministry of higher education and scientific research in Kurdistan, Iraq, HCDP program is gratefully acknowledged for the studentship to JAJ. Also the authors acknowledge the financial support of the TSB (UK) under the RECONIF project (BA011K) and of the EU under Framework 7 for project CoLaBATS (FP7-ENV-2013 603482). 
a)

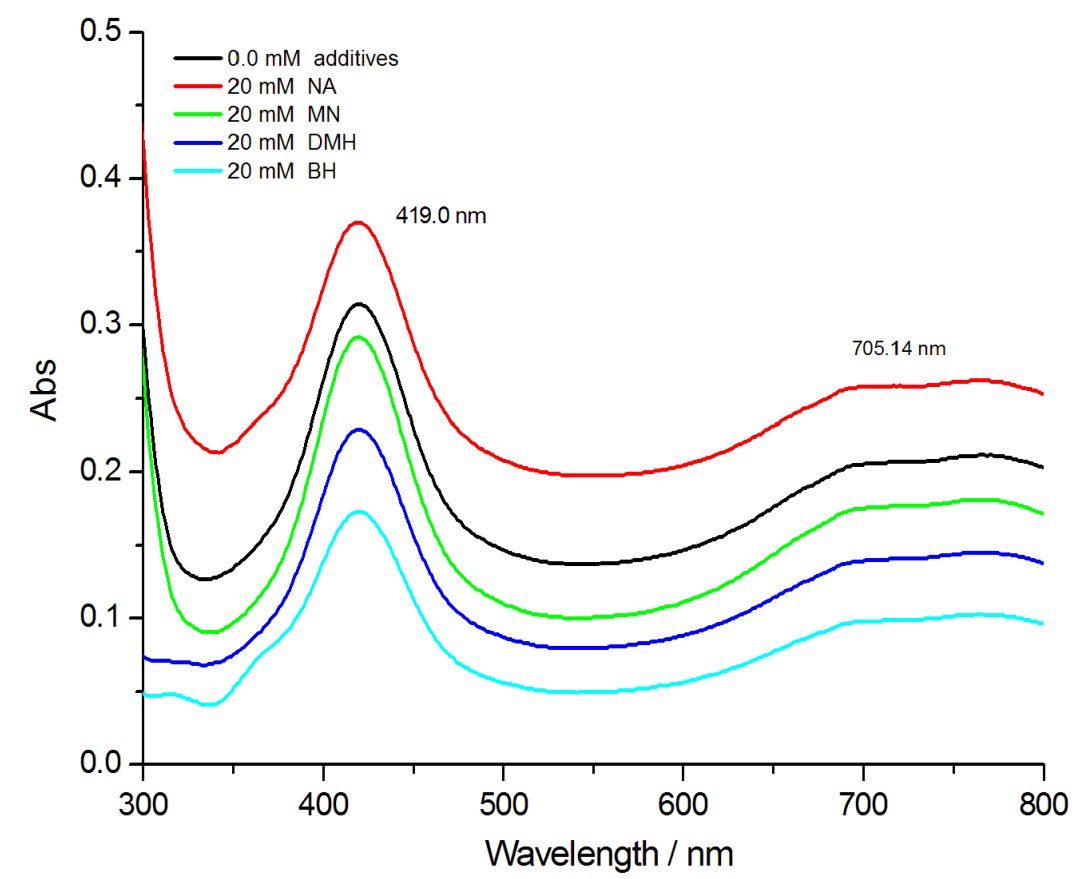

b)

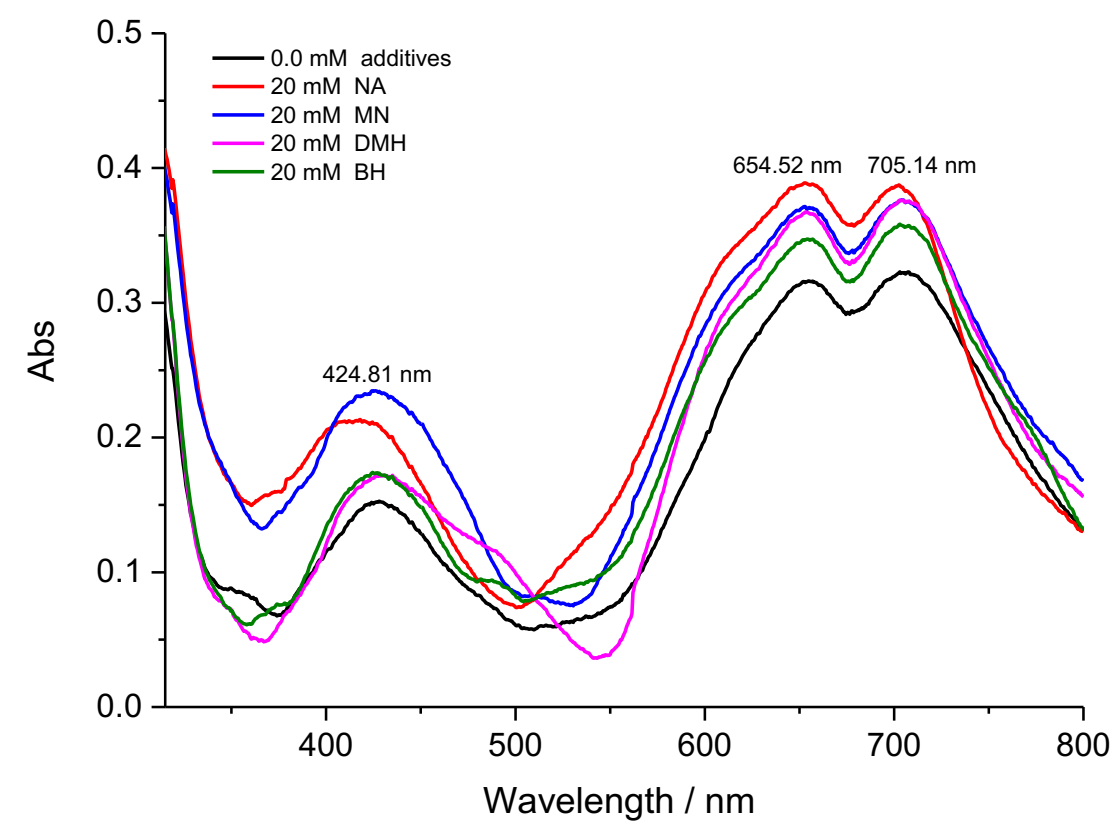

Figure 1: UV-visible spectra of $15 \mathrm{mM} \mathrm{NiCl}_{2} \cdot 6 \mathrm{H}_{2} \mathrm{O}$ (black) in a 1:2 molar ratio Choline chloride and ethyleneglycol and spectra of the same solutions with additional $20 \mathrm{mM} \mathrm{NA}($ red), MN (blue), $\mathrm{DMH}$ (pink) and BA (green) recorded at (a) room temperature and (b) $90^{\circ} \mathrm{C}$. 


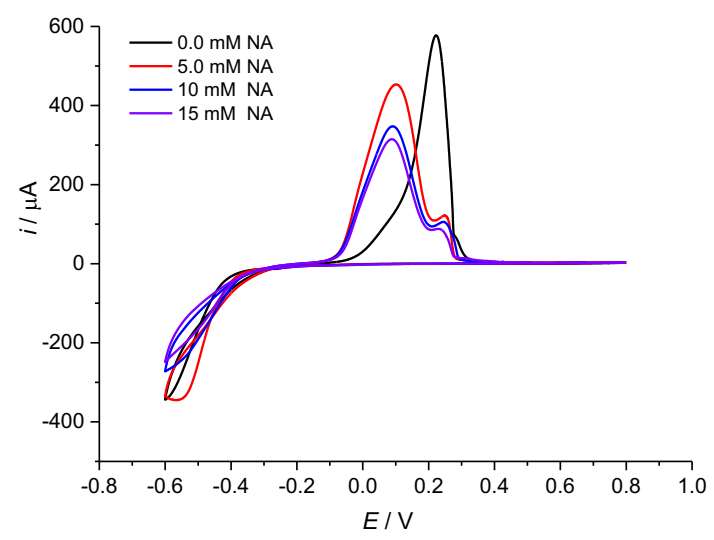

(a)

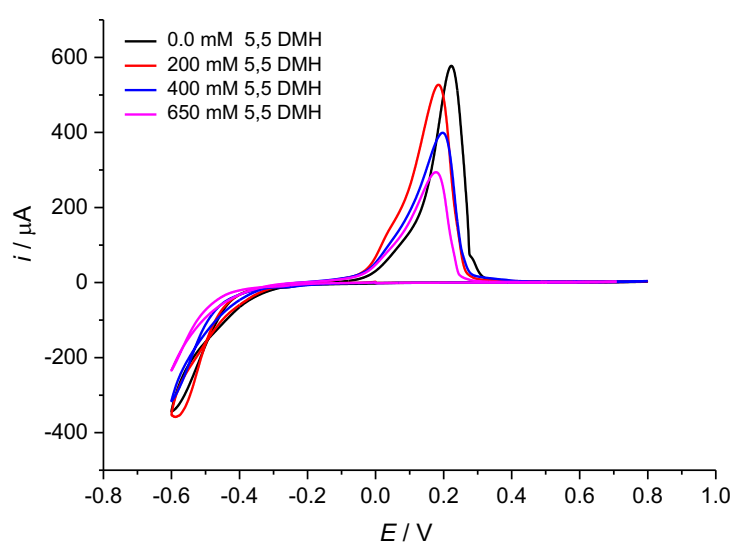

(c)

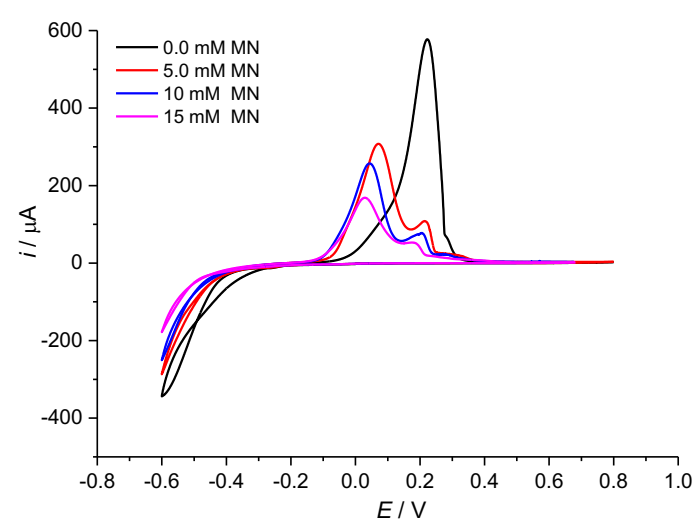

(b)

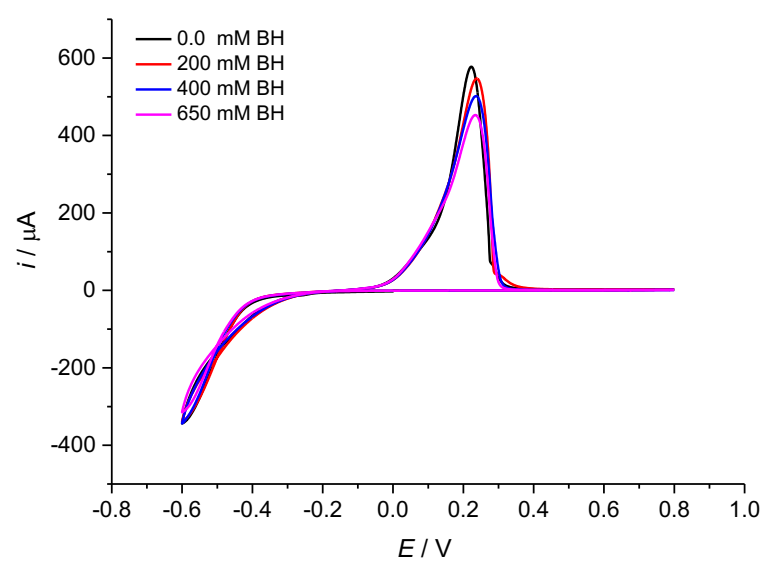

(d)

Figure 2: Cyclic voltammogram at $90^{\circ} \mathrm{C}$ of $0.6 \mathrm{M} \mathrm{NiCl}_{2} \cdot 6 \mathrm{H}_{2} \mathrm{O}$ in a $1: 2$ molar mixture of choline chloride and ethyleneglycol with varying amounts of (a) NA, (b) MN, (c) DMH and (d) BA. Measured using a $1 \mathrm{~mm}$ Pt disc working electrode, Pt flag counter electrode and referenced against $A g$ wire at $10 \mathrm{mV} \mathrm{s}^{-1}$ 


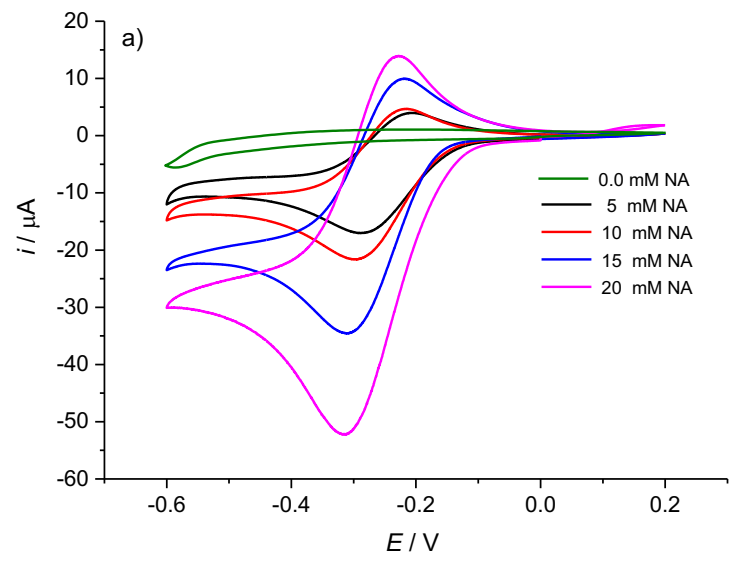

(a)

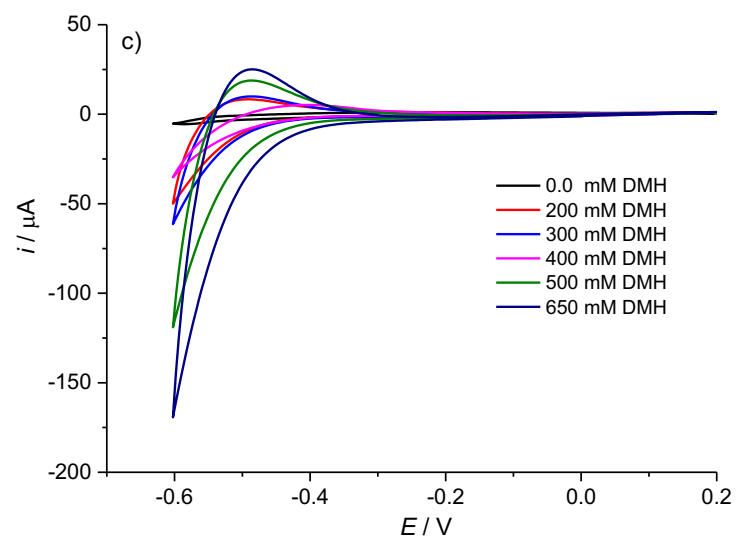

(c)

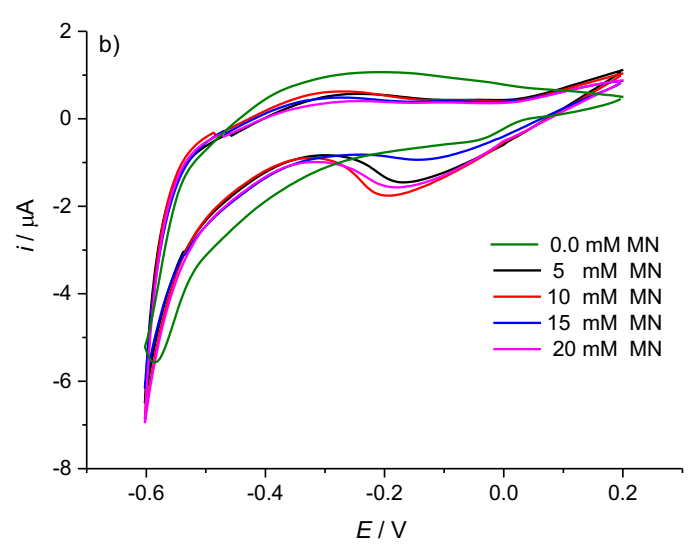

(b)

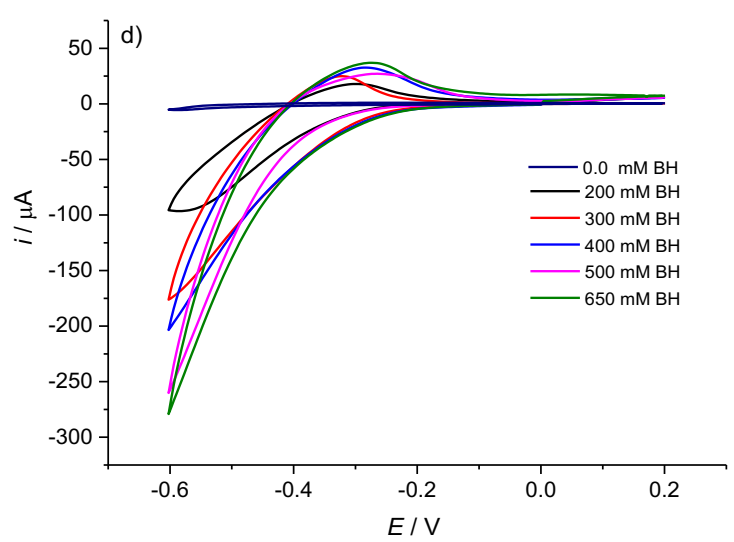

(d)

Figure 3: Cyclic voltammogram at $90{ }^{\circ} \mathrm{C}$ of a $1: 2$ molar mixture of choline chloride and ethyleneglycol with varying amounts of (a) NA, (b) MN, (c) DMH and (d) BA. Measured using a $1 \mathrm{~mm}$ Pt disc working electrode, Pt flag counter electrode and referenced against $\mathrm{Ag}$ wire at $10 \mathrm{mV} \mathrm{s}^{-1}$ 


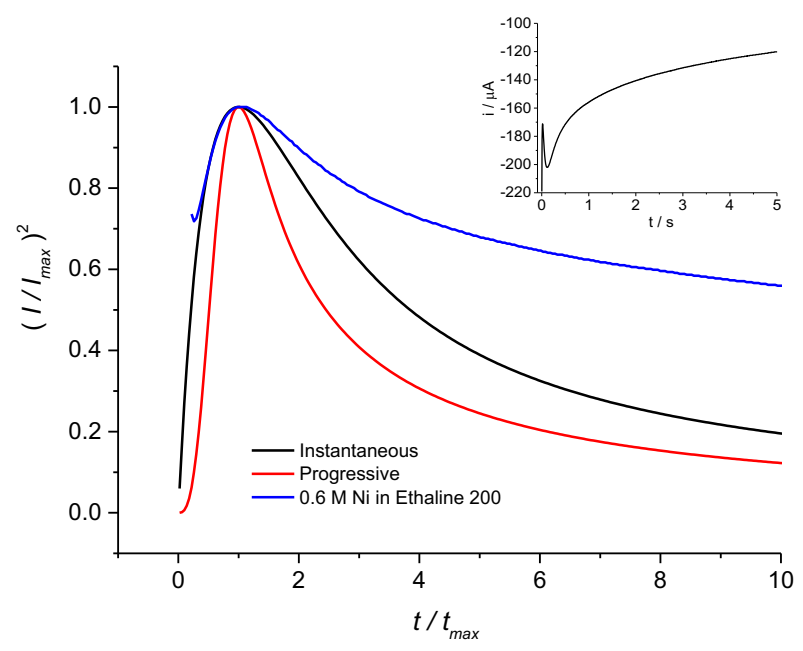

(a)

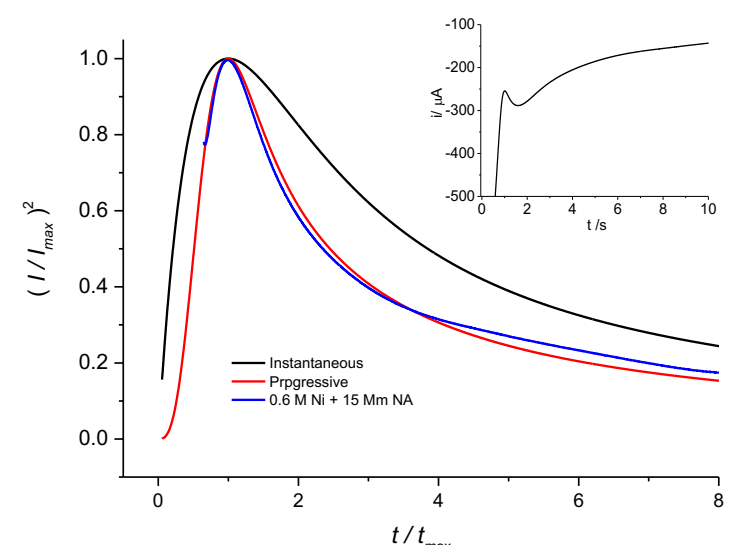

(b)

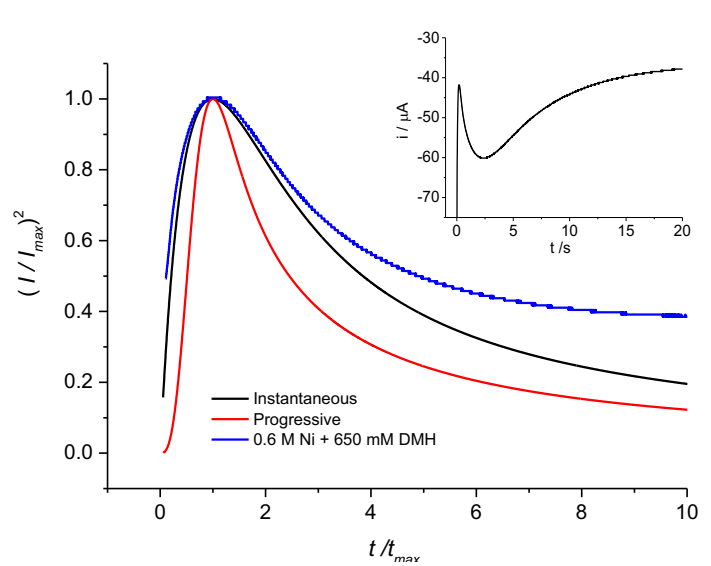

(d)

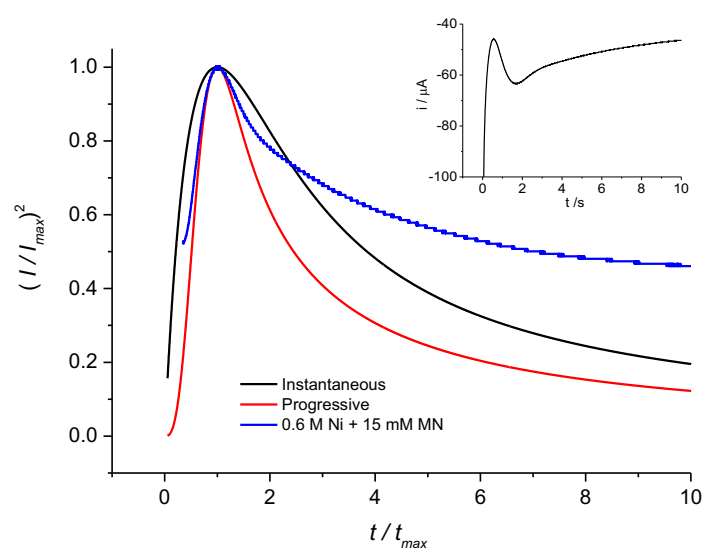

(c)

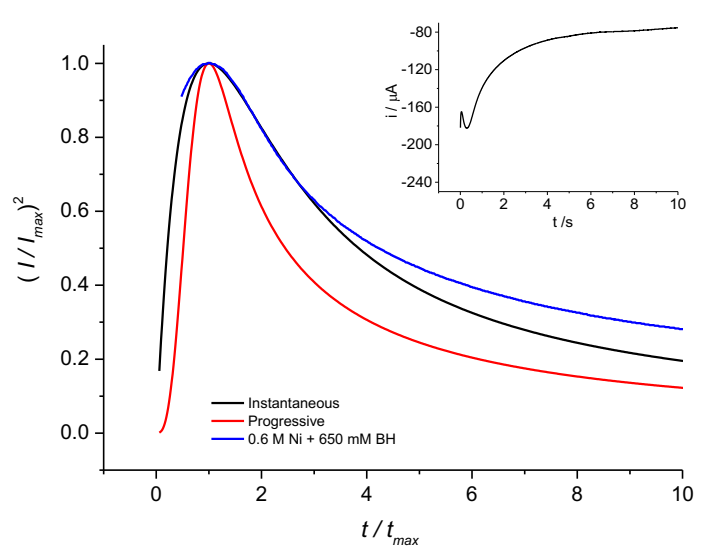

(e)

Figure 4: Reduced variant plots for current transients for choronoamperometry (insert) at $90{ }^{\circ} \mathrm{C}$ of (a) $0.6 \mathrm{M} \mathrm{NiCl}_{2} \cdot 6 \mathrm{H}_{2} \mathrm{O}$ in a 1:2 molar ratio choline chloride and ethyleneglycol and (b) with $15 \mathrm{mM} \mathrm{NA}$, (c) $15 \mathrm{mM} \mathrm{MN}$, (d) $0.65 \mathrm{M} \mathrm{DMH}$ and (e) $0.65 \mathrm{M} \mathrm{BA}$. The potential was initially held at $0.6 \mathrm{~V}$ (w.r.t. Ag wire) for $10 \mathrm{~s}$ followed by a step to $-0.4 \mathrm{~V}$ for ca. 30 mins. Pt working electrode dia $1 \mathrm{~mm}$, Pt flag counter electrode and silver wire reference. 


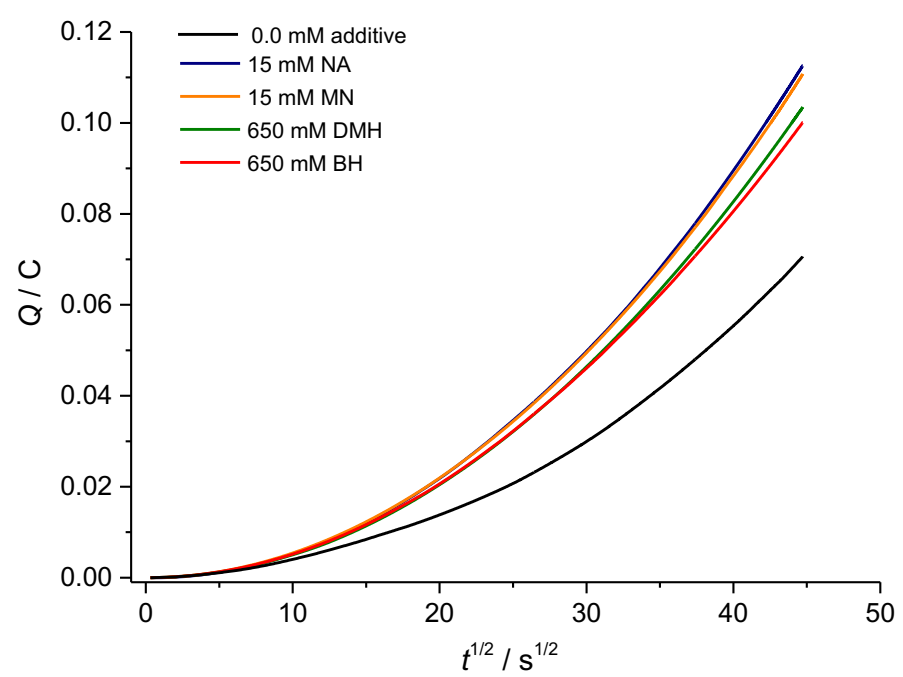

Figure 5: Chronocoulometry at $90{ }^{\circ} \mathrm{C}$ of $0.6 \mathrm{M} \mathrm{NiCl}_{2} \cdot 6 \mathrm{H}_{2} \mathrm{O}$ in a $1: 2$ molar ratio of choline chloride and ethyleneglycol (black) and with added $15 \mathrm{mM} \mathrm{NA}$ (blue), $15 \mathrm{mM} \mathrm{MN}$ (orange), 0.6 M DMH (green) and $0.6 \mathrm{M} \mathrm{BA}(r e d)$. The potential was initially held at $+0.6 \mathrm{~V}$ (w.r.t. Ag wire) for 10 $\mathrm{s}$ followed by a step to $-0.4 \mathrm{~V}$ for ca. 30 mins. Recorded at a $1 \mathrm{~mm}$ Pt disc working electrode with a Pt flag counter electrode and a silver wire reference.

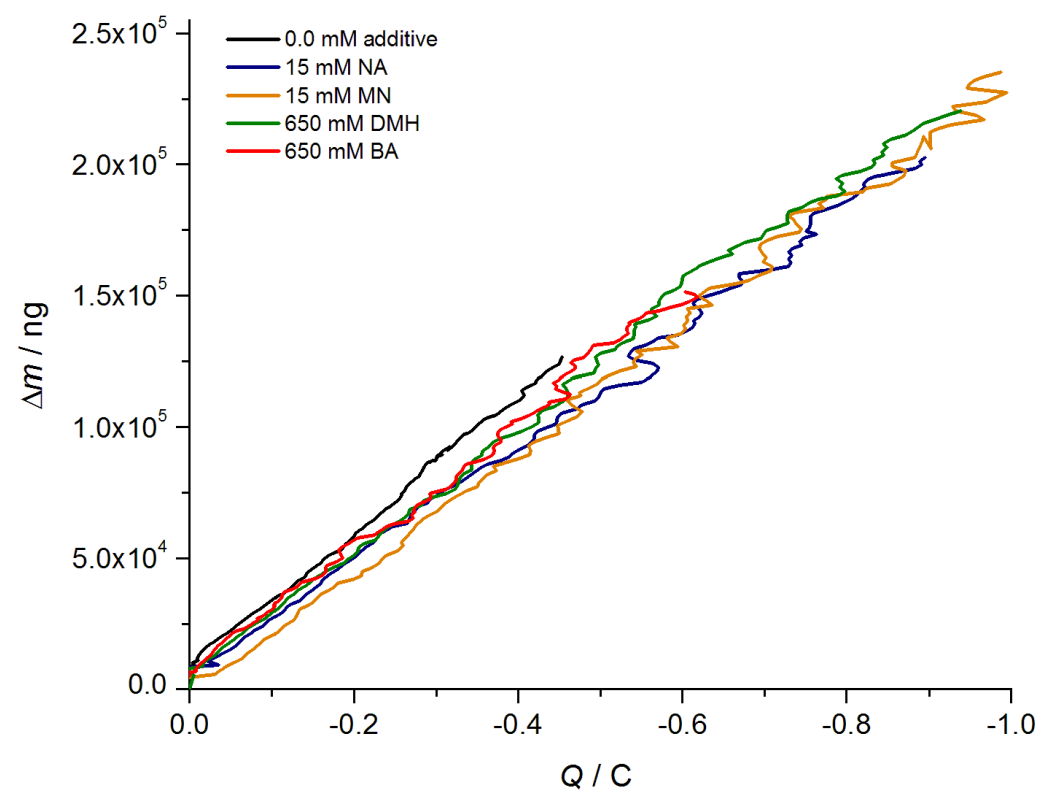

Figure 6: Mass-charge plots for Ni deposits on a Pt coated quartz crystal (10MHz) without (black) and with $15 \mathrm{mM} \mathrm{NA}$ (blue), 0.65 M BH (red), $0.65 \mathrm{M} \mathrm{DMH}$ (green) and $15 \mathrm{mM} \mathrm{MN}$ (brown). The potential was initially held at $0.6 \mathrm{~V}$ for $10 \mathrm{~s}$ followed by a step to $-0.4 \mathrm{~V}$ for $c a .15$ mins. Pt coated crystal working electrode has a surface area $0.23 \mathrm{~cm} 2$, Pt flag counter electrode and silver wire reference. 


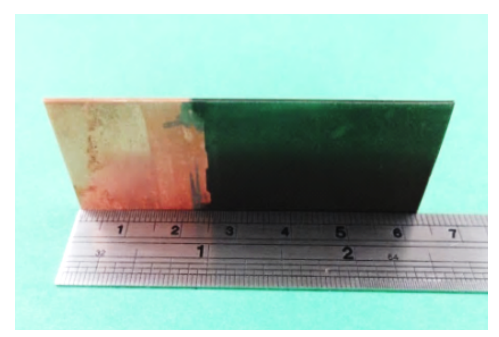

(a)

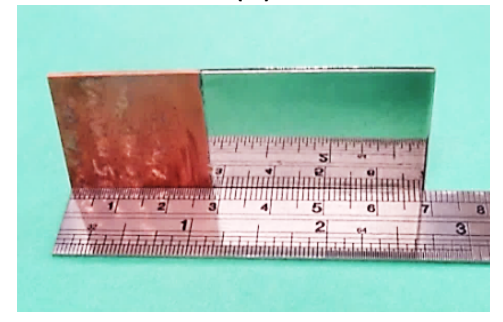

(d)

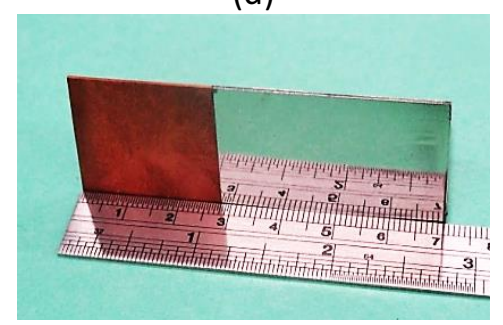

(g)

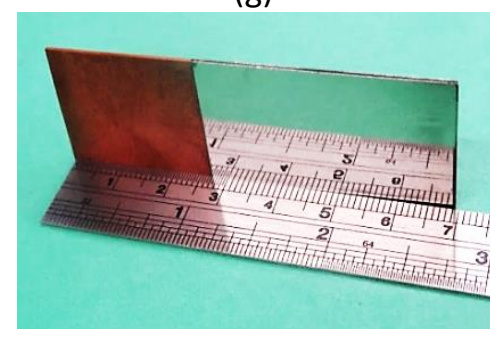

(j)

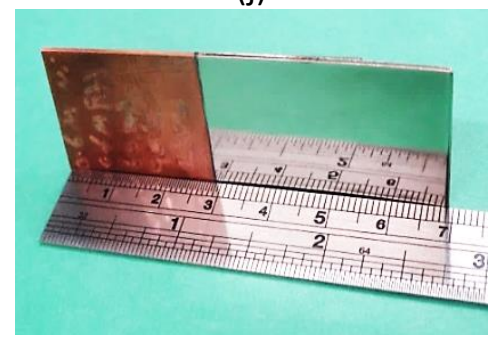

(m)

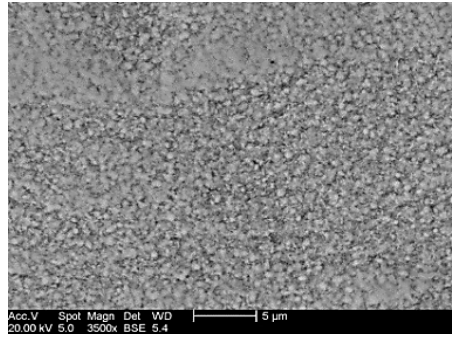

(b)

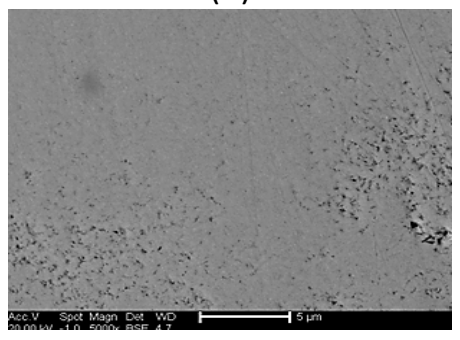

(e)

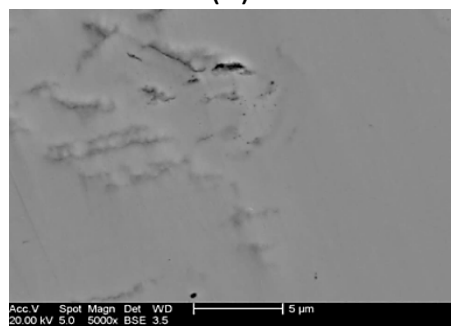

(h)

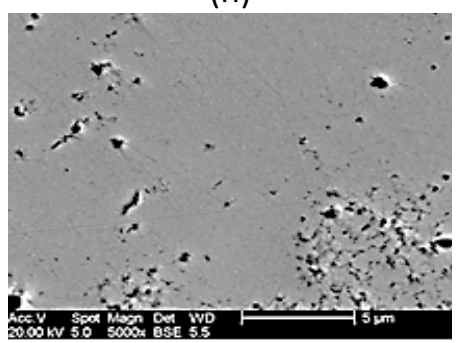

(k)

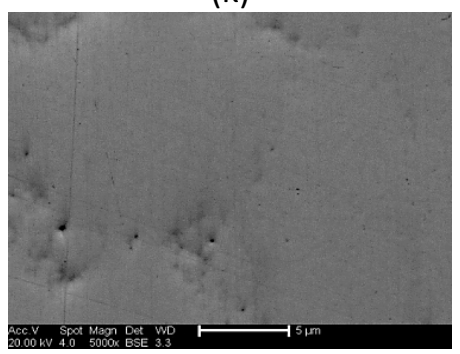

(n)

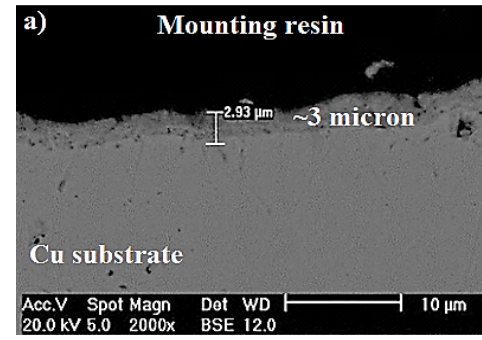

(c)

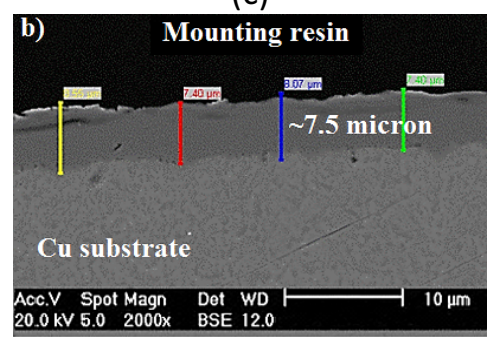

(f)

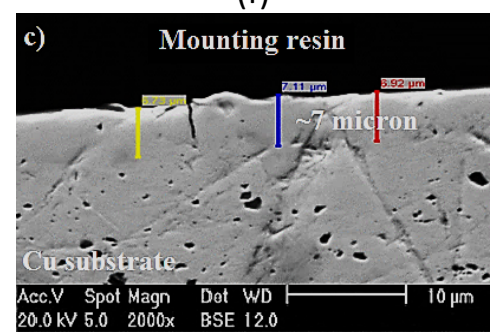

(i)

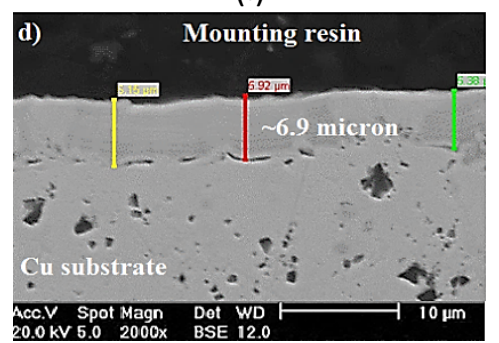

(I)

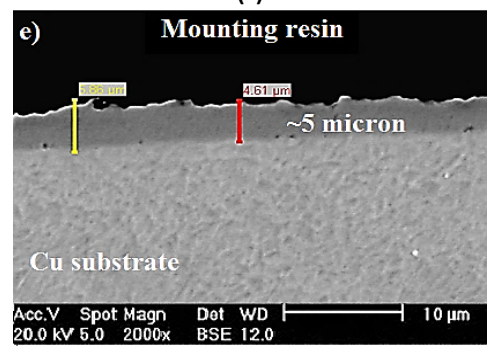

(o)

Figure 7: Optical and SEM images of electrodeposited $\mathrm{Ni}$ from $0.6 \mathrm{M} \mathrm{NiCl}_{2}$ in a $1 \mathrm{ChCl}$ :2EG molar ratio (a-c) without additives and with (d-f) $15 \mathrm{mM} \mathrm{NA}$, (g-i) $15 \mathrm{mM} \mathrm{MN},(\mathrm{j}-\mathrm{l}) 0.65 \mathrm{M} \mathrm{DMH}$ and (m-o) $0.65 \mathrm{M} \mathrm{BH}$. Plating performed at $90{ }^{\circ} \mathrm{C}$ on a copper substrate at $1.2 \mathrm{~A} \mathrm{dm}^{-2}$ for 20 mins with an iridium oxide coated titanium counter electrode. 


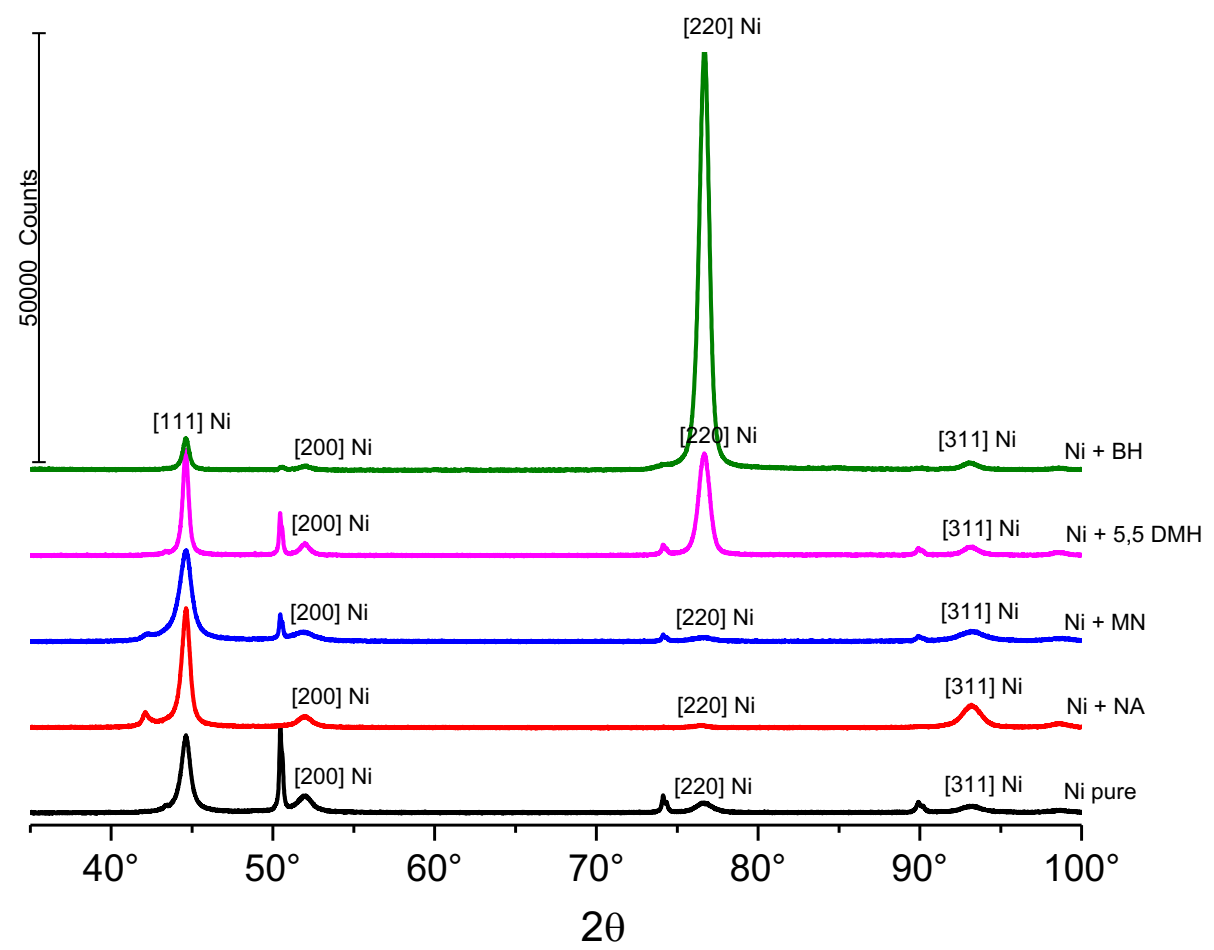

Figure 8: XRD results of the Ni deposited from Ethaline system on $\mathrm{Cu}$ substrate at $90^{\circ} \mathrm{C}$ with different additives. The samples were grown for a period of $2 \mathrm{hrs}$ such that they were thick enough to eliminate the substrate effects. 
Table 1: Structures of additives and electrolyte components used in this study.<smiles>O=C(O)c1cccnc1</smiles>

nicotinic acid (NA)<smiles>COC(=O)c1cccnc1</smiles>

methyl nicotinate (MN)<smiles>CC1(C)NC(=O)NC1=O</smiles>

5,5-dimethyl hydantoin

(DMH)<smiles>OB(O)O</smiles>

boric acid (BA)<smiles>C[N+](C)(C)CCO</smiles><smiles>CC(Cl)(Cl)CCO</smiles>

choline chorlide

Table 2: Current efficiency and coating hardness of coatings from $0.6 \mathrm{M}\left[\mathrm{NiCl}_{2} .6\left(\mathrm{H}_{2} \mathrm{O}\right)\right]$ in $1 \mathrm{ChCl}$ : $2 \mathrm{EG}$ in absence and presence additive. Current efficiency data were evaluated from the mass/charge plots shown in Figure 6.

\begin{tabular}{|l|c|c|}
\hline Electrolyte & Current efficiency \% & Vickers Hardness/ HV \\
\hline Pure Ni $(0.6 \mathrm{M}$, no additive) & 90 & $389 \pm 5$ \\
\hline $\mathrm{Ni}+\mathrm{NA}(15 \mathrm{mM})$ & 78 & $454 \pm 30$ \\
\hline $\mathrm{Ni}+\mathrm{MN}(15 \mathrm{mM})$ & 79 & $473 \pm 20$ \\
\hline $\mathrm{Ni}+\mathrm{DMH}(0.6 \mathrm{M})$ & 81 & $430 \pm 15$ \\
\hline $\mathrm{Ni}+\mathrm{BA}(0.6 \mathrm{M})$ & 82 & $458 \pm 35$ \\
\hline
\end{tabular}

Table 3: The relative intensity of Bragg diffraction peaks of pure Ni with different additives.

\begin{tabular}{|l|c|c|c|c|}
\hline \multicolumn{1}{|c|}{ Component } & $\begin{array}{c}\text { Relative } \\
\text { intensity } \\
{[\mathbf{1 1 1}]}\end{array}$ & $\begin{array}{c}\text { Relative } \\
\text { intensity } \\
{[\mathbf{2 0 0}]}\end{array}$ & $\begin{array}{c}\text { Relative } \\
\text { intensity } \\
{[\mathbf{2 2 0}}\end{array}$ & $\begin{array}{c}\text { Relative } \\
\text { intensity } \\
{[\mathbf{3 1 1}]}\end{array}$ \\
\hline Pure Ni (0.6 M, no additive) & 0.600 & 0.108 & 0.124 & 0.090 \\
\hline $\mathrm{Ni}+\mathrm{NA}(15 \mathrm{mM})$ & 0.810 & 0.110 & 0.024 & 0.051 \\
\hline
\end{tabular}




\begin{tabular}{|l|l|l|l|l|}
\hline $\mathrm{Ni}+\mathrm{MN}(15 \mathrm{mM})$ & 0.802 & 0.050 & 0.030 & 0.116 \\
\hline $\mathrm{Ni}+\mathrm{DMH}(0.6 \mathrm{M})$ & 0.358 & 0.0371 & 0.541 & 0.061 \\
\hline $\mathrm{Ni}+\mathrm{BA}(0.6 \mathrm{M})$ & 0.056 & 0.00033 & 0.922 & 0.0177 \\
\hline
\end{tabular}

\section{References}

1. M. Schlesinger and M. Paunovic, Modern Electroplating, Wiley, 2011.

2. H. Yang, X. Guo, N. Birbilis, G. Wu and W. Ding, Applied Surface Science, 2011, 257, 90949102.

3. R. Bottager, Erdmann's Journal für Praktische Chemie, 1843, 30, 267.

4. R. Weil, Plating, 1970, 57, 1231.

5. S. A. Watson and J. edwards, Transactions of the Institute of Metal Finishing, 1957, 34, 167.

6. L. M. Muresan and S. C. Varvara, Levelling and Brightening Mechanisms in Metal Electrodeposition, Nova Science Publishers, New York, 2005.

7. J. P. Hallett and T. Welton, Chemical Reviews, 2011, 111, 3508-3576.

8. E. L. Smith, A. P. Abbott and K. S. Ryder, Chemical Reviews, 2014, 114, 11060-11082.

9. F. Liu, Y. Deng, X. Han, W. Hu and C. Zhong, Journal of Alloys and Compounds, 2016, 654, 163-170.

10. P. De Vreese, N. R. Brooks, K. Van Hecke, L. Van Meervelt, E. Matthijs, K. Binnemans and R. Van Deun, Inorganic Chemistry, 2012, 51, 4972-4981.

11. A. P. Abbott, K. El Ttaib, G. Frisch, K. J. McKenzie and K. S. Ryder, Physical Chemistry Chemical Physics, 2009, 11, 4269-4277.

12. A. R. Hillman, K. S. Ryder, C. J. Zaleski, V. Ferreira, C. A. Beasley and E. Vieil, Electrochimica Acta, 2014, 135, 42-51.

13. S. Ghosh and S. Roy, Materials Science and Engineering B-Advanced Functional Solid-State Materials, 2014, 190, 104-110.

14. S. Salome, N. M. Pereira, E. S. Ferreira, C. M. Pereira and A. F. Silva, Journal of Electroanalytical Chemistry, 2013, 703, 80-87.

15. A. P. Abbott, J. C. Barron and K. S. Ryder, Transactions of the Institute Metal Finishing, 2009, 87, 201-207.

16. M. Starykevich, A. N. Salak, D. K. Ivanou, A. D. Lisenkov, M. L. Zheludkevich and M. G. S. Ferreira, Electrochimica Acta, 2015, 170, 284-291.

17. J. Zhang, C. Gu, Y. Tong, J. Gou, X. Wang and J. Tu, RSC Advances, 2015, 5, 71268-71277.

18. E. S. C. Ferreira, C. M. Pereira and A. F. Silva, Journal of Electroanalytical Chemistry, 2013, 707, 52-58.

19. S. Fashu, C.-d. Gu, J.-I. Zhang, M.-I. Huang, X.-I. Wang and J.-p. Tu, Transactions of Nonferrous Metals Society of China, 2015, 25, 2054-2064.

20. A. P. Abbott, G. Capper, K. J. McKenzie and K. S. Ryder, Journal of Electroanalytical Chemistry, 2007, 599, 288-294.

21. N. M. Pereira, S. Salome, C. M. Pereira and A. Fernando Silva, Journal of Applied Electrochemistry, 2012, 42, 561-571.

22. N. M. Pereira, C. M. Pereira and A. Fernando Silva, Electrochemistry Letters, 2012, 1, D5-D7.

23. N. M. Pereira, P. M. V. Fernandes, C. M. Pereira and A. Fernando Silvaz, Journal of the Electrochemical Society, 2012, 159, D501-D506.

24. C. D. Gu, Y. H. You, X. L. Wang and J. P. Tu, Surface \& Coatings Technology, 2012, 209, 117123.

25. A. P. Abbotta, J. C. Barron, G. Frisch, K. S. Rydera and A. Fernando Silva, Electrochimica Acta, 2011, 56, 5272-5279. 
26. R. Bock, G. Lanzinger, R. Freudenberger, T. Mehner, D. Nickel, I. Scharf and T. Lampke, Journal of Applied Electrochemistry, 2013, 43, 1207-1216.

27. E. L. Smith, J. C. Barron, A. P. Abbott and K. S. Ryder, Analytical Chemistry, 2009, 81, 84668471.

28. C. Hardacre, in Annual Review of Materials Research 2005, 35, pp. 29-49.

29. J. M. Hartley, C.-M. Ip, G. C. H. Forrest, K. Singh, S. J. Gurman, K. S. Ryder, A. P. Abbott and G. Frisch, Inorganic Chemistry, 2014, 53, 6280-6288.

30. A. J. Dent, K. R. Seddon and T. Welton, Journal of the Chemical Society-Chemical Communications, 1990, 315-316.

31. D. C. Apperley, C. Hardacre, P. Licence, R. W. Murphy, N. V. Plechkova, K. R. Seddon, G. Srinivasan, M. Swadzba-Kwasny and I. J. Villar-Garcia, Dalton Transactions, 2010, 39, 86798687.

32. M. P. Jensen, J. Neuefeind, J. V. Beitz, S. Skanthakumar and L. Soderholm, Journal of the American Chemical Society, 2003, 125, 15466-15473.

33. A. D. Ballantyne, G. C. H. Forrest, G. Frisch, J. M. Hartley and K. S. Ryder, Physical Chemistry Chemical Physics, 2015, 17, 30540-30550.

34. A. P. Abbott, A. Ballantyne, R. C. Harris, J. A. Juma, K. S. Ryder and G. Forrest, Electrochimica Acta, 2015, 176, 718-726.

35. C.D. Gu and J.-P. Tu, RSC Advances, 2011, 1, 1220-1227.

36. J. M. Hartley, C. M. Ip, G. C. H. Forrest, K. Singh, S. J. Gurman, K. S. Ryder, A. P. Abbott and G. Frisch, Inorganic Chemistry, 2014, 53, 6280-6288.

37. L. Huang, R. Zhang, M. Gu, F. Z. Yang, S. K. Xu and S. M. Zhou, Acta Physico-Chimica Sinica, 2002, 18, 665-668.

38. A. L. Portela, G. I. Lacconi and M. L. Teijelo, Journal of Electroanalytical Chemistry, 2001, 495, 169-172.

39. K. M. Yin and B. T. Lin, Surface and Coatings Technology, 1996, 78, 205-210.

40. D. Grujicic and B. Pesic, Electrochimica Acta, 2002, 47, 2901-2912.

41. B. Scharifker and G. Hills, Electrochimica Acta, 1983, 28, 879-889.

42. M. Ciobanu, J. P. Wilburn, M. L. Krim and D. E. Cliffel, Handbook of electrochemistry, Fundamentals, Elsevier, Amsterdam, 2007. 3-29.

43. G. Sauerbrey, Zeitschrift für Physik, 1959, 155, 206-222.

44. W. B. Jensen, Journal of Chemical Education, 2012, 89, 1208-1209.

45. Y. Hou, H. Kondoh, T. Ohta and S. Gao, Applied Surface Science, 2005, 241, 218-222.

46. W. A. Wesley and E. J. Roehl, Journal of The Electrochemical Society, 1942, 82. 